\title{
Mieap forms membraneless organelles to compartmentalize and facilitate cardiolipin metabolism
}

Naoki Ikari, Katsuko Honjo, Yoko Sagami, Yasuyuki Nakamura, and Hirofumi Arakawa*

Division of Cancer Biology, National Cancer Center Research Institute

5-1-1 Tsukiji, Chuo-ku, Tokyo 104-0045, Japan

* Correspondence should be addressed to:

Hirofumi Arakawa, M.D., Ph.D.

Division of Cancer Biology

National Cancer Center Research Institute

5-1-1 Tsukiji, Chuo-ku, Tokyo 104-0045, JAPAN

Tel: +81-3-3547-5273, Fax: +81-3-3546-1369

E-mail: harakawa@ncc.go.jp 


\begin{abstract}
Liquid droplets function as membraneless organelles that compartmentalize and facilitate efficient biological reactions in cells. They are formed by proteins with an intrinsically disordered region(s) (IDR) via liquid-liquid phase separation. Mieap/SPATA18, a p53-inducible protein, plays a critical role in the suppression of human and murine colorectal tumors via mitochondrial quality control. However, the regulatory mechanism underlying this process remains unclear. Here, we report that Mieap is an IDR-containing protein that drives the formation of liquid droplets in the mitochondria. Mieap liquid droplets (MLDs) specifically phase separate the mitochondrial phospholipid cardiolipin. Lipidomic analysis of cardiolipin suggested that Mieap promotes enzymatic reactions involved in cardiolipin metabolism, including biosynthesis and remodeling. Accordingly, four cardiolipin biosynthesis enzymes, TAMM41, PGS1, PTPMT1, and CRLS1, and two remodeling enzymes, PLA2G6 and TAZ, are phase separated by MLDs. Mieap-deficient mice exhibited altered cristae structure in the liver and kidney mitochondria and a trend of obesity. These results suggest that Mieap drives the formation of membraneless organelles to compartmentalize and promotes cardiolipin metabolism at the inner mitochondrial membrane, thus playing a possible role in mitochondrial quality control.
\end{abstract}




\section{Introduction}

Mitochondria-eating protein (Mieap, also designated as SPATA18) was originally identified as a p53-inducible protein; its mRNA expression is directly regulated by the tumor suppressor p53 in response to various cellular stresses, including DNA damage (Miyamoto et al., 2011). Mieap expression is lost in nearly $50 \%$ of human cancer cell lines due to promoter methylation (Miyamoto et al., 2011). Mieap-deficient LS174T colorectal cancer cells exhibit increased mitochondrial reactive oxygen species (ROS) generation and decreased mitochondrial ATP synthesis (Miyamoto et al., 2011). The mitochondrial ROS in the Mieap-deficient colorectal cancer and gastric cancer cells enhance migration and invasion activities of the cancer cells under hypoxic conditions (Kamino et al., 2016; Okuyama et al., 2019). Mieap-deficient $\mathrm{Apc}^{\mathrm{Min} /+}$ mice exhibit the promotion of intestinal tumor initiation and malignant transformation (Tsuneki et al., 2015). The tumors in Mieap-deficient $\mathrm{Apc}^{\mathrm{Min} /+}$ mice have revealed abnormal morphology of the mitochondria, such as enlargement of the size, round shape, and decrease in cristae structure (Tsuneki et al., 2015). Recently, Mieap expression was reported to be defective in thyroid oncocytic cell tumors, which exhibit accumulation of abnormal mitochondria in tumor cells (Mussazhanova et al., 2020). These observations suggest that Mieap plays a critical role in tumor suppression via its mitochondrial quality control function. Mieap-regulated mitochondrial quality control is inactivated in the tumor tissues of nearly $70 \%$ colorectal cancer and $25 \%$ breast cancer patients (Kamino et al., 2016; Gaowa et al., 2018). However, the mechanism underlying the regulation of mitochondrial quality control by Mieap remains unclear.

Liquid droplets (LDs) in cells are protein condensates, which are composed of proteins, nucleic acids, and other macromolecular components (Shin and Brangwynne, 2017; Boeynaems et al., 2018; Alberti et al., 2019). LDs are formed by proteins with an intrinsically disordered region(s) (IDR) via liquid-liquid phase separation (LLPS) (Shin and Brangwynne, 2017; Boeynaems et al., 2018). Importantly, LDs function as membraneless organelles that compartmentalize and facilitate cellular biological reactions (Shin and Brangwynne, 2017; Boeynaems et al., 2018). LDs are not surrounded by a lipid bilayer structure, which enables dynamic exchange of reactants and products with their surroundings, facilitating biological reactions in cells (Shin and Brangwynne, 2017; Boeynaems et al., 2018). Furthermore, theoretically, LDs are able to appear and disappear anywhere within a cell in response to cellular stress and/or subcellular circumstances, exhibiting spatiotemporal dynamic properties (Shin and Brangwynne, 2017). On the basis of these features, the concept of membraneless organelles is fundamentally different from the long-standing concept of membrane-bound organelles, such as the nucleus, lysosome, mitochondria, and endoplasmic reticulum, which stably exist and strictly segregate biomolecules and biological reactions by a lipid bilayer structure. It is suggested that a number of membraneless organelles may exist within a cell, which could regulate various cellular biological reactions and activities, including transcriptional regulation (Hnisz et al., 2017; Sabari et al., 2018), signal transduction (Martin and Mittag, 2019; Case et al., 2019; Huang et al., 2019), immunity (Du and Chen, 2018), centrosome activity (Woodruff et al., 2017), and mitosis (Rai et al., 2018). This list is now rapidly growing. 
Cardiolipin (CL) is a unique and important phospholipid because of the following reasons. (1) CL is a phospholipid dimer, which has two phosphate residues and four fatty acyl chains (Macfarlane, 1958; Gonzalvez and Gottlieb, 2007). (2) Because of this unique structure, it forms a cone shape, which plays a critical role in forming the curvature of the lipid membrane, contributing to the maintenance of the mitochondrial cristae structure (Dudek, 2017; Ikon and Ryan, 2017; Cullis and Kruijff, 1979). (3) CL is the only phospholipid that is specific to the mitochondria and is mainly located at the inner mitochondrial membrane and contact sites (Gonzalvez and Gottlieb, 2007; Ardail et al., 1990). (4) CL interacts with many mitochondrial membrane proteins, including the electron transport chain complexes involved in oxidative phosphorylation and the ADP/ATP carrier; the interaction with CL promotes the activity of these proteins (Paradies et al., 2014; Dudek, 2017; Gonzalvez and Gottlieb, 2007; Planas-Iglesias et al., 2015). (5) CL stabilizes the structural assembly and activity of the respiratory super-complexes at the inner mitochondrial membrane (Paradies et al., 2014; Dudek, 2017). (6) CL interacts with cytochrome $c$ at the outer surface of the inner mitochondrial membrane, which plays a pivotal role in the life and death of cells by maintaining stable respiratory ATP production and inducing apoptosis, respectively (Gonzalvez and Gottlieb, 2007; Paradies et al., 2014). Therefore, altered CL metabolism and/or deterioration of CL quality causes various mitochondrial dysfunctions and diseases via abnormal cristae structures, decreased ATP synthesis activity, and increased ROS generation (Ren et al., 2014; Pennington et al., 2019; Paradies et al., 2019).

Here, we report that Mieap is an IDR-containing protein that drives LDs formation in the mitochondria (designated as Mieap liquid droplets: MLDs). The MLDs phase separate the mitochondrial phospholipid CL. The results of the present study suggest that MLDs function as membraneless organelles that compartmentalize and promote CL synthesis and remodeling reactions at the inner mitochondrial membrane, leading to the stabilization of oxidative phosphorylation and suppression of mitochondrial ROS generation. We suggest that MLDs are possibly involved in mitochondrial quality control. 


\section{Results}

\section{Mieap forms liquid droplets}

Mieap has been previously reported to form vacuole-like structures designated as Mieap-induced vacuoles (MIVs), which were considered to directly take up mitochondria (Kitamura et al., 2011), suggesting that the phenomenon is non-canonical mitophagy. To examine the process of MIV formation and "non-canonical mitophagy" in live cells, we constructed a recombinant adenovirus for expressing EGFP-tagged Mieap and observed the cells expressing EGFP-Mieap by confocal live-cell imaging. As shown in Figure 1A and Video S1, multiple spherical green EGFP-Mieap condensates appeared around the red mitochondrial signals (MitoTracker Red). These oval green condensates fused to each other, enlarged, and eventually formed a few large spherical structures. In contrast, the red mitochondrial signals decreased during this process, and the MIVs contained the signals from MitoTracker Red. Thus, the results were not contradictory to our previous interpretation of non-canonical mitophagy. However, the results indicated that the MIVs are protein condensates, not ring-shaped structures, as previously reported in immunofluorescence (IF) experiments (Kitamura et al., 2011).

To verify the consistency of these results with previous observations, we performed IF studies on the condensate structures comprising EGFP-Mieap. Subsequently, EGFP-Mieap reproducibly formed green condensates, while the antibodies (anti-Mieap antibody and anti-GFP antibody) showed ring-shaped staining around the green condensates, as previously reported (Figure 1B) (Kitamura et al., 2011). Furthermore, we performed immunostaining using an anti-FLAG antibody for the MIV structures, which comprise N-FLAG-Mieap (N-terminal FLAG-tagged Mieap protein) and C-FLAG-Mieap (C-terminal FLAG-tagged Mieap protein); a clear ring-shaped staining was observed only in the case of N-FLAG-Mieap but not for C-FLAG-Mieap (Figure 1C). Considering the inconsistency between the results of fluorescent tagging and those of the antigen-antibody reaction, we suspected that antibodies are unable to permeabilize the Mieap condensates. At the edge of the protein condensates, Mieap is possibly positioned such that its $\mathrm{N}$-terminal side is facing outward.

Thus, we conducted transmission electron microscopy (TEM) analysis combined with post-embedding immunoelectron microscopy (IEM) analysis with an anti-Mieap antibody. As shown in Figure 1D, according to TEM following osmium tetroxide $\left(\mathrm{OsO}_{4}\right)$ staining, the MIV structure was observed to consist of two phases: one was an electron-dense major phase that was strongly stained by $\mathrm{OsO}_{4}$, and the other was an $\mathrm{OsO}_{4}$-negative electron-lucent minor phase. $\mathrm{OsO}_{4}$ stains unsaturated lipids (Belazi et al., 2009). The gold colloids indicating the Mieap protein were distributed over the electron-dense major phase, as observed through post-embedding IEM (Figure 1E). Thus, the inconsistency in results was attributed to the antibody impermeability of the condensates. Concurrently, Mieap was confirmed to form protein condensates by both fluorescent tagging and antigen-antibody reaction, which was fundamentally distinct from "mitophagy." The Mieap condensates exhibited a spherical or oval shape, contained bubbles, and showed fusion (Figure 1F; Video S2). These characteristics indicate that Mieap condensates have liquid-like 
properties (Alberti et al., 2019).

Integrating these findings, we designate the Mieap protein condensates as MLDs. The MLDs showed not only typical features of LDs but also antibody impermeability. Additionally, $\mathrm{OsO}_{4}$ strongly stained the electron-dense portion of Mieap, according to TEM. These results suggest the potentially specific nature of the MLDs, rendering them distinct from other known LDs, such as stress granules and nucleoli (Molliex et al., 2015; Lee et al., 2016).

\section{Mieap contains four intrinsically disordered regions, clusters of positively charged residues, and amphiphilic sequences}

Next, to understand the nature of the Mieap protein, we performed in silico sequence analyses, considering that Mieap forms MLDs. The Mieap orthologs were found in eukaryota, but not in bacteria, archaea, or viruses (Figure S1A) (Kriventseva et al., 2019). Hence, the Mieap function evolved in eukaryotes that acquired mitochondria. Moreover, among eukaryota, Mieap orthologs were found in metazoa but not in fungi (Figure S1A). These results suggest the role of Mieap in mitochondrial quality control, which is beneficial to multicellular organisms. No mitochondrial transfer peptide was annotated by TargetP 2.0 (Almagro Armenteros et al., 2019) or iPSORT (Bannai et al., 2002) in the Mieap sequence.

Using prediction tools, we determined that Mieap has four IDRs spreading over two coiled-coil (CC) domains (amino acids 92-311: IDR1 to IDR3) and in the C-terminus (amino acids 499-538: IDR4) (Figures 2A and 2B) (Huang et al., 2014; Uversky et al., 2007; Lupas et al., 1991). Although the amino acid sequence of the IDRs was evolutionarily divergent compared to that of the structured regions, the distribution of the IDRs and the clusters of positively charged residues in IDR3 and IDR4 were evolutionarily conserved (Figures 2A, S1B, S1D) (Holehouse et al., 2017).

With respect to the amino acid residues, enrichment in arginine ( $R$, positively charged), as well as serine ( $S$, uncharged polar), was common to all four IDRs (Figures S1C and S1D). Additionally, IDR1 was enriched in aspartic acid (D, negatively charged), and IDR2 was enriched in glutamic acid (E, negatively charged) (Figures S1C and S1D). D and E were mixed with the positively charged residues in IDR1 and IDR2, respectively (Figures S1C and S1D). In contrast, since IDR3 and IDR4 were largely devoid of negatively charged residues, they formed clusters of positively charged residues characterized by repeats of $\mathrm{R}$ and $\mathrm{S}$ (Figures 2A, S1C and S1D) (Holehouse et al., 2017).

In addition, there was an evolutionarily conserved hydropathic characteristic in the Mieap sequence as a whole, the N-terminal half being hydrophilic and the C-terminal half being hydrophobic (Figures 2A and S1B) (Kyte and Doolittle, 1982). The gross halves were separated by IDR3 and the adjacent structured region, which were inevitably placed in tandem (Figures $2 \mathrm{~A}$ and 2B). This implies that the Mieap protein exhibits biosurfactant features.

These results suggest that Mieap has the potential to drive LLPS (Alberti et al., 2019), with its IDRs harboring affinity for negatively charged molecules and with its whole sequence harboring amphiphilicity (Figure 2B). 


\section{Material state and dynamics of MLD are determined by specific regions of Mieap}

To map the sites responsible for the material state and dynamics of the MLDs, using a confocal microscope, we examined cells expressing EGFP-Mieap (full-length) and the three deletion-mutant forms, which lacked whole coiled-coil domains together with the intervening IDR2 and a part of the adjacent IDR1 and IDR3 $(\triangle \mathrm{CC})$, the C-terminal side next to the coiled-coil domains $(\Delta 275)$, and the C-terminal IDR4 $(\Delta 496)$ (Figure $2 \mathrm{C})$.

All the deletion mutants formed condensates, exhibiting their respective morphologies (Figure 2D and Video S3). The EGFP-Mieap (full-length) formed spherical or oval condensates containing spherical bubbles that assembled near the nucleus. In contrast, EGFP-Mieap $\triangle \mathrm{CC}$ formed lobular condensates without bubbles, which assembled near the nucleus to form a single reticular assembly per cell. EGFP-Mieap $\Delta 275$ formed spherical condensates without bubbles, which were distributed throughout the cytoplasm. EGFP-Mieap $\Delta 496$ formed spherical condensates that were smaller but more numerous than the MLDs. The condensates formed by EGFP-Mieap $\Delta 496$ contained bubbles, similar to those formed by EGFP-Mieap (full-length).

We further examined the relationship between the localization of each mutant and the mitochondria by performing live-cell imaging of the EGFP-mutants and MitoTracker Red. EGFP-Mieap, EGFP-Mieap $\triangle \mathrm{CC}$, and EGFP-Mieap $\Delta 496$ condensates appeared near the mitochondria, whereas EGFP-Mieap $\Delta 275$ condensates were detected at the site of the cytoplasm that is apart from the mitochondria (Figure 2E and Video S3). The results were confirmed by TEM analysis (data not shown).

These results indicate that the N-terminal IDRs (IDR1-3) spreading over the CC domains (deleted in the $\triangle \mathrm{CC}$ mutant) endows MLDs with liquid-like properties, the structured region at the C-terminal side next to the coiled-coil domains (deleted in the $\triangle 275$ mutant) allows MLDs to reside near the mitochondria, and the C-terminal IDR4 (deleted in the $\Delta 496$ mutant) partially endows MLDs with fusing ability. Both the N-terminal IDRs (hydrophilic) deleted in the $\triangle \mathrm{CC}$ mutant and the structured region (hydrophobic) deleted in the $\Delta 275$ mutant are necessary for forming the multiphase structures of the MLDs.

\section{Availability of Mieap is limited in the MLD}

To further investigate the protein dynamics of the MLDs, we performed fluorescence recovery after photobleaching (FRAP) studies for the EGFP-Mieap (full-length)-, $\Delta$ CC-, $\Delta 275-$, and $\Delta 496$-condensates. During observation up to $60 \mathrm{~s}$ after spot-bleach, with the bleach depth being $82.2 \pm 8.1 \%$, the fluorescence intensity of the EGFP-Mieap (full-length)-, $\Delta C C-, \Delta 275-$, and $\Delta 496$-condensates recovered to $9.9 \pm 4.0 \%, 4.0 \pm 1.0 \%, 94.3 \pm 4.0 \%$, and $17.8 \pm 3.1 \%$ of the initial value, respectively (Figures $3 \mathrm{~A}$ and $3 \mathrm{~B}$ ). Accordingly, the fluorescence recovery of the $\Delta 275$-condensates, which lacked a large part of the structured region, showed the highest fluorescence recovery and reached near the initial value within the 60-s observation period, indicating the most liquid-like state. In contrast, the $\Delta \mathrm{CC}$-condensates, which lacked a large part of 
the N-terminal IDRs (IDR1-IDR3), showed the lowest fluorescence recovery, indicating the most solid-like state. The EGFP-Mieap (full-length)- and $\Delta 496$-condensates, which lacked the C-terminal IDR4, showed intermediate fluorescence recovery. However, the $\Delta 496$-condensates showed relatively higher fluorescence recovery when compared with the EGFP-Mieap (full-length)-condensates (Figures 3A and 3B).

Intriguingly, the EGFP-Mieap (full-length)- and $\Delta 496$-condensates showed continuous linear fluorescence recovery after an initial steep rise (Figure 3B). This result suggested the existence of a certain rate-limiting factor, which limited the rapidity of the fluorescence recovery. To narrow down the candidates of the rate-limiting factor, we attempted weaker laser exposure, which resulted in lowered bleach depth to $21.2 \pm 4.4 \%$; subsequently, the fluorescence recovery rate increased $60 \mathrm{~s}$ after spot-bleaching (FL, 50.4 $\pm 8.8 \% ; \Delta \mathrm{CC}, 32.6 \pm 8.8 \% ; \Delta 275,94.9 \pm 13.7 \% ; \Delta 496$, $61.5 \pm 10.1 \%$ ) (Figure $3 \mathrm{C}$ ). The increase in fluorescence recovery rate when the number of bleached molecules was small suggested that availability may be a rate-limiting factor.

To further investigate the extent to which EGFP-Mieap (full-length)-, $\Delta \mathrm{CC}$-, and $\Delta 496$-condensates harbor mobile fractions, we observed the slow fluorescence recovery up to 15 min. During this long-term observation, we photobleached the entire condensates because the spot-bleached area could not be precisely tracked for $15 \mathrm{~min}$ (data not shown). The EGFP-Mieap (full-length)- and the $\Delta 496$-condensates showed continuous fluorescence recovery, which reached $80.4 \pm 10.2 \%$ and $94.0 \pm 9.5 \%$ of the initial value in $15 \mathrm{~min}$, respectively (Figure 3D). In contrast, the $\triangle \mathrm{CC}$-condensates reached equilibrium at $37.4 \pm 6.3 \%$ of the initial value in $15 \mathrm{~min}$ (Figure $3 \mathrm{D}$ ). The data indicated that the EGFP-Mieap (full-length)-condensates, as well as the $\Delta 496$-condensates, mainly consist of mobile fractions; however, the protein availability from their surroundings is limited.

In summary, deleting a large part of the C-terminal structured region $(\Delta 275)$ leads to a liquid-like change. Deleting a large part of the N-terminal IDRs $(\triangle C C)$ leads to a solid-like change. MLDs are suggested to exist as an intermediate state between $\triangle 275$ and $\triangle C C$ condensates, that is, a gel-like state (Boeynaems et al., 2018). Mieap, as visualized by the EGFP tag, is mobile in MLDs; however, the availability of Mieap from their surroundings is limited.

\section{MLDs exist in mitochondria and phase separate mitochondrial phospholipid cardiolipin}

As shown in Figure 1A, MLDs appeared to arise from the region where the mitochondria are located. To clarify the spatial relationship between MLDs and the mitochondria, we performed live-cell imaging using cells co-expressing EGFP-Mieap and an outer mitochondrial membrane marker mApple-TOMM20. As shown in Figures 4A, 4B, and S2 and Video S4, mApple-TOMM20 surrounded the whole circumference of the MLDs, regardless of the size of MLDs. These results suggest that MLDs appear and exist within the mitochondria and that enlarged MLDs still exist in the mitochondria.

Next, we investigated the target molecules for phase separation by MLDs. First, we screened available fluorescence-tagged mitochondrial proteins and mitochondrial fluorescence 
probes by confocal live-cell imaging analysis. EGFP-BNIP3, EGFP-NIX, AcGFP1-Mito, DsRed2-Mito, and SYBR Green I (a probe for mitochondrial DNA) were localized in the mitochondria (Figures S3B and S3C) but not distributed to the MLDs (Figures 4A-4E and Video S5).

However, 10-N-nonyl acridine orange (NAO) and EGFP-cytochrome $c$ were specifically incorporated into MLDs (Figures 4C and 4E and Video S6). NAO targets CL (Kaewsuya et al., 2007), and cytochrome $c$ is a CL-binding protein (Gonzalvez and Gottlieb, 2007; Paradies et al., 2014). Positively charged residues are enriched in the IDRs of Mieap (Figures 2A, S1C, and S1D), CL carries a net negative charge (Kaewsuya et al., 2007), the sequence data indicate amphiphilicity of Mieap (Figures 2A and 2B), and MLDs consist of an electron-dense phase that is positive for $\mathrm{OsO}_{4}$, according to TEM analysis; this implies that MLDs contain unsaturated lipids (Belazi et al., 2009) (Figure 1D). Therefore, we suspected that CL is a bona-fide target for phase separation by MLDs.

To elucidate whether Mieap directly binds CL, we performed a fat blot assay (Munnik and Wierzchowiecka, 2013), in which the binding of GST-Mieap to CL, phosphatidylcholine (PC), and phosphatidylethanolamine (PE) was assayed on the lipid-dotted membranes. GST-Mieap was bound to CL but not to PC or PE (Figure 4D). This result suggests that Mieap drives the phase separation of CL by directly binding to CL.

CL forms complexes with many mitochondrial proteins (>60 proteins), such as cytochrome $c$, ATP synthase, and prohibitin complex (Planas-Iglesias et al., 2015). Among them, ATP5F1B and PHB2 were previously listed as candidates for "Mieap-binding" proteins in our IP-2DICAL Mieap-interactome data (Miyamoto et al., 2012). This prompted us to investigate, using confocal microscopy and their fluorescence-tagged proteins, whether additional CL-binding proteins (ATP5F1B and PHB2) are phase separated by MLDs.

EGFP-ATP5F1B and EGFP-PHB2 were observed to be localized at the mitochondria (Figures S3E and S3F) and then distributed in the MLDs (Figures $4 \mathrm{~F}$ and $4 \mathrm{G}$ and Video S6). Although EGFP-cytochrome $c$, EGFP-ATP5F1B, and EGFP-PHB2 were co-localized with TagRFP-T-Mieap, we observed the exclusion of EGFP-cytochrome $c$, EGFP-ATP5F1B, and EGFP-PHB2 from the Mieap-containing major phase and their accumulation into the minor phase (bubbles) in the MLDs (Figures 4E, 4F, and 4G and Video S6). Thus, these results suggest that these proteins are not binding partners of Mieap but are incorporated into MLDs together with CL as a complex and subsequently excluded from the Mieap-containing major phase to varying degrees.

\section{Mieap is involved in CL metabolism}

LDs are suggested to function as membraneless organelles, which compartmentalize essential biochemical reactions by increasing the concentration of enzymes and substrates, resulting in the promotion and activation of their reactions (Boeynaems et al., 2018; Shin and Brangwynne, 2017). Therefore, we hypothesized that MLDs may regulate CL metabolism.

We performed mass spectrometric analyses of CL in A549 cells with and without 
exogenous Mieap expression to the extent that visible MLDs were formed. The total amount of CL per cell was found to be higher in the exogenous Mieap-expressing cells than in the cells without exogenous Mieap expression (Figure 5A). Broad CL species showed higher absolute values in the cells with exogenous Mieap expression than in the cells without exogenous Mieap expression (Figure 5B and Table S1). In contrast, most of the relative amounts of each CL species did not change, or rather, decrease. However, the exogenous Mieap specifically increased the proportions of CL72:4, CL72:5, CL72:6, CL70:5, CL70:6, CL68:5, and CL68:6 (Figure 5B).

Accordingly, we next explored whether Mieap exhibits such effects on CL metabolism under physiological conditions. We performed mass spectrometric analyses of CL of LS174T cells with and without physiological Mieap protein using Mieap-control and Mieap-knockdown (KD) cells. In accordance with the results of exogenous Mieap expression, the total amount of CL per cell was found to be higher in the control cells than in the Mieap-KD cells (Figure 5C), and the control cells showed higher absolute values for broad CL species than the Mieap-KD cells (Figure 5D and Table S1). Furthermore, physiological Mieap specifically increased the relative values of CL72:4, CL72:5, CL70:4, CL70:5, CL68:3, and CL68:4 (Figure 5D).

Collectively, these findings on exogenous and physiological Mieap protein suggest that Mieap is involved in the regulation of CL metabolism.

\section{MLDs compartmentalize CL metabolic reactions}

Since Mieap regulates CL metabolism, we speculated that MLDs may function as membraneless organelles to compartmentalize and promote CL metabolic reactions, including CL biosynthesis and remodeling. CL metabolic enzymes are well characterized and studied in yeast cells, and human orthologs of many yeast enzymes have been reported (Ren et al., 2014). In brief, phosphatidic acid (PA) is synthesized in the endoplasmic reticulum and subsequently transported by PRELI (Ups1) via the outer mitochondrial membrane to the inner mitochondrial membrane, as the substrate of CL metabolism (Potting et al., 2013) (Figure 6A). In CL biosynthesis, PA is converted to nascent CL on the matrix face of the inner mitochondrial membrane through sequential enzymatic reactions that produce three intermediates, CDP-diacylglycerol (CDP-DG), phosphatidylglycerophosphate (PGP), and phosphatidylglycerol (PG), and are catalyzed by a series of four enzymes, TAMM41 (Tam41), PGS1 (Pgs1), PTPMT1 (Gep4), and CRLS1 (Crd1) (Dudek, 2017; Ren et al., 2014; Schlame and Greenberg, 2017; Ye et al., 2016) (Figure 6A). The final step of CL metabolic reaction is remodeling of nascent CL to mature CL, which is catalyzed by PLA2G6/iPLA2 $\beta$ (Cld1) and TAZ (Taz1) (Malhotra et al., 2009; Ren et al., 2014; Ye et al., 2016; Schlame and Greenberg, 2017) (Figure 6A). If MLDs function as membraneless organelles to compartmentalize and facilitate CL metabolic reaction, we reasoned that MLDs phase separate these enzymes involved in CL biosynthesis and remodeling.

Thus, we evaluated the involvement of the following set of EGFP-tagged enzymes required for CL metabolism in MLDs by performing confocal live-cell imaging: EGFP-TAMM41, EGFP-PGS1, EGFP-PTPMT1, and EGFP-CRLS1 (involved in CL biosynthesis); EGFP-PLA2G6 
(related to $\mathrm{CL}$ hydrolysis by phospholipase A2 activity); and EGFP-TAZ (involved in CL remodeling). As shown in Figures 6B-6G and S6A-S6F and Video S7, all these enzymes were localized in the mitochondria and subsequently incorporated into MLDs.

Interestingly, all these CL metabolic enzymes were predominantly localized and concentrated into the internal bubbles (the electron-lucent minor phase) in the MLDs (Figures 6B-6G and Video S7). Additionally, unlike CL-binding proteins, most of the enzymes were localized on the entire circumference of the MLDs, as indicated by line-scan analysis (Figures 6B-6G). These results suggest that the external edge of MLDs faces the inner mitochondrial membrane and that the enzymes are incorporated into the bubbles at the interface between the inner mitochondrial membrane and the external edge of the MLDs.

We further examined EGFP-tagged PRELI (EGFP-PRELI), which loads PA (Potting et al., 2013). Intriguingly, EGFP-PRELI was incorporated into MLDs (Figure 6H and Video S7). This observation suggests that MLDs can also be supplied with PA as the substrate for CL synthesis (Ren et al., 2014) (Figure 6A).

Additionally, we tested two EGFP-tagged mitochondrial enzymes, mitochondrial protease LONP1 (EGFP-LONP1) (Bota and Davies, 2002) and mitochondrial CL hydrolase/mitochondrial phospholipase (MitoPLD)/phospholipase 6 (PLD6) (EGFP-PLD6). PLD6 hydrolyzes CL to generate PA at the outer mitochondrial membrane (Choi et al., 2006). Both were located in the mitochondria (Figures S5H and S5I), but neither EGFP-LONP1 nor EGFP-PLD6 was distributed in the MLDs (Figures 6I and 6J and Video S7).

\section{Possible role of Mieap in mitochondrial quality control via regulation of CL metabolism}

CL alteration induces various phenotypes due to mitochondrial dysfunction (Ren et al., 2014; Paradies et al., 2019; Pennington et al., 2019) . Since its discovery, the function of Mieap has been suggested to be involved in mitochondrial quality control (Miyamoto et al., 2011; Kitamura et al., 2011; Tsuneki et al., 2015; Kamino et al., 2016). Therefore, we hypothesized that Mieap plays a role in mitochondrial quality control by regulating CL metabolism. Indeed, as shown in Figures 5C and 5D, the deficiency of physiological Mieap protein altered the CL metabolism in LS174T cells. To test this hypothesis, we evaluated various mitochondrial status related to CL integrity in Mieap-deficient cells and mice.

First, we examined respiration activity, mitochondrial ATP production rate, ROS level, and cristae morphology in the control and Mieap-KD LS174T cells under physiological conditions, all of which reflect CL integrity. Flux analysis indicated that the respiration activity and ATP production rate of the Mieap-KD cells were significantly lower than that of the control cells (Figures 7A and 7B). The ROS levels increased in the Mieap-KD cells (Figure S6A). TEM analysis revealed that the cristae of the Mieap-KD cells decreased, and the morphology became unclear and irregular, compared to that of the control cells (Figures 7C and 7D).

Second, we analyzed the cristae morphology in the kidney and liver tissues of Mieap-knockout (KO) mice by performing TEM analysis because these tissues are rich in 
mitochondria. In the Mieap ${ }^{-/-}$kidney mitochondria, irregularly dilated lamellar structures without distinct $\mathrm{OsO}_{4}$ staining were observed (Figure 7E). A decrease in normal cristae (identified by the presence of lamellar structures with distinct $\mathrm{OsO}_{4}$ staining) was a characteristic common to Mieap $^{-/-}$mitochondria in the kidney and liver (Figures 7E-7H).

Finally, we performed a large-scale cross-sectional observation of a total of $1353 \mathrm{Mieap}^{+/+}$, Mieap $^{+/-}$, and Mieap ${ }^{-/-}$mice to identify the long-term consequences of Mieap deficiency. As shown in Figure 7I, the average body weights of the Mieap ${ }^{+/-}$and Mieap ${ }^{-/}$mice were higher than those of the Mieap ${ }^{+/+}$mice throughout their life span. The differences were prominent during the middle age from 53 to 62 weeks (Figure S6B) (mean value \pm SE; Mieap ${ }^{+/+} 31.048 \pm 0.64 \mathrm{~g}\left[\mathrm{n}=49\right.$ ], Mieap ${ }^{+/-}$ $33.378 \pm 0.517 \mathrm{~g}[\mathrm{n}=115]$, Mieap $^{-/} 34.579 \pm 0.660 \mathrm{~g}$ [n=68]) or during the middle and old age from 40 weeks to 104 weeks (Figure S6C) (mean value $\pm \mathrm{SE}$; Mieap ${ }^{+/+} 33.154 \pm 0.410 \mathrm{~g}$ [n=162], Mieap $^{+/-} 34.099 \pm 0.289 \mathrm{~g}[\mathrm{n}=303]$, Mieap $\left.^{-/-} 35.090 \pm 0.415 \mathrm{~g}[\mathrm{n}=175]\right)$. Reduced mitochondrial respiratory activity in adipose tissues has been reported to be a factor responsible for obesity (Schöttl et al., 2015; Lee et al., 2019; Soro-Arnaiz et al., 2016). Moreover, a study reported that altered CL remodeling causes obesity through increased oxidative stress and mitochondrial dysfunction ( $\mathrm{Li}$ et al., 2010). These results suggest that obesity is possibly a long-term consequence of mitochondrial dysfunction due to CL alteration in Mieap-deficient mice.

In summary, all these phenotypes in the physiological Mieap-deficient models corroborate our hypothesis that Mieap plays a physiological role in mitochondrial quality control by regulating CL metabolism. 


\section{Discussion}

\section{MLDs compartmentalize and promote CL metabolic reactions}

Metabolic reactions are believed to be highly organized through spatiotemporal clustering and compartmentalizing sequential enzymes and substrates/intermediates at a subcellular local site, which maximizes the efficiency of the reactions (Welch, 1977). Without this mechanism, small and toxic intermediates, which are derived from metabolic reactions, rapidly diffuse and escape throughout the cytoplasm. Thus, the concept of subcellular compartmentalization of metabolic reactions has been anticipated for a long time; it was initially designated as "Metabolon," which implies complexes of sequential metabolic enzymes and substrates/intermediates (Srere, 1987). The "Metabolon" concept predicted that the sequential enzymes and cellular structural elements form a supramolecular complex for metabolic reactions. In fact, many studies have demonstrated that enzyme clustering in vivo may play a pivotal role in effective sequential enzymatic metabolic reactions (Jin et al., 2017; Lee et al., 2012; Kohnhorst et al., 2017; Schmitt and An, 2017). Among them, "Purinosome" involved in purine metabolism is the first demonstration of enzyme clustering revealed by live-cell imaging of six sequential enzymes for de novo purine synthesis (An et al., 2008).

Although the importance of a multi-enzyme complex by enzyme clustering in metabolic enzyme reactions has been recognized as described above, it remains unclear how the complex of enzymes efficiently and safely enables the sequential enzymatic reactions by preventing the diffusion of intermediates. Recently, a study reported that crowding and concentration of multiple enzymes and substrates/intermediates in a restricted space could mediate efficient sequential enzymatic reactions by preventing the diffusion of intermediates (Castellana et al., 2014). In the model, assembling multiple copies of both upstream and downstream enzymes in the sequential enzymatic reactions into a single cluster, which is designated as "agglomerate" by the authors, provides a model, the concept of which is 'once an upstream enzyme produces an intermediate; although the probability of the intermediate being processed by any individual downstream enzymes is low, the probability that the intermediate will be processed by one of the many downstream enzymes in the "agglomerate" can be high' (Castellana et al., 2014). Therefore, based on this model, molecular crowding of enzymes, substrates, and intermediates in a restricted space could make the efficient sequential enzymatic reactions mediated by multiple enzymes possible.

The "agglomerate" concept is promising, but an important question remains: how can such a number of diverse molecules, including multiple enzymes, substrates, and intermediates, be gathered, concentrated, and compartmentalized within a single restricted space? What drives the formation of the "agglomerate"? We speculate that LDs could organize the formation of "agglomerate" as metabolic LDs (Prouteau and Loewith, 2018). Accumulating evidence suggests that LDs can function as membraneless organelles, which promote biochemical reactions by concentrating and compartmentalizing enzymes and substrates in cells (Strulson et al., 2012; Bracha et al., 2019; Zhao et al., 2019; Hinzpeter et al., 2017). Since LDs are not surrounded by a bilayer lipid structure, theoretically, they exhibit spatiotemporal dynamic properties within a cell in 
response to cellular stress and/or subcellular circumstances. More importantly, LDs contain hundreds of molecules, whereas a few scaffold proteins can drive the formation of these membraneless organelles (Shin and Brangwynne, 2017). If there is a protein(s) that could organize the formation of metabolic LDs as a scaffold(s) (Zhao et al., 2019), in which multiple enzymes and intermediates involved in a sequential metabolic reaction are compartmentalized and concentrated, the concept of 'aggromerate' could get a grip on reality, which is the mechanism that enables efficient metabolic reactions.

In the present study, we obtained the following evidence, which supports our hypothesis that MLDs could function as a machinery that regulates CL metabolism: (1) Mieap drives the formation of LDs (designated as MLDs) within the mitochondria. (2) The MLDs contain CL. (3) MLDs contain all four sequential enzymes for CL biosynthesis (TAMM41, PGS1, PTPMT1, and CRLS1). (4) MLDs contain two enzymes for CL remodeling (PLA2G6 and TAZ). (5) MLDs contain at least three CL-binding proteins localized at the inner mitochondrial membrane (cytochrome $c$, PHB2, and ATP5F1B). (6) The presence or absence of the Mieap protein is closely related to an increase or decrease in a broad species of CL, respectively. (7) The presence of Mieap protein specifically increases the proportion of several species of CLs. (8) Mieap deficiency is related to morphological changes in the cristae structure in vivo. This evidence suggests that Mieap, as a scaffold protein, drives the formation of metabolic LDs that compartmentalize and concentrate the enzymes, substrate, and intermediates that are involved in CL biosynthesis and remodeling, leading to molecular crowding within the MLDs, which promotes efficient enzymatic reactions in CL metabolism.

In the MLDs, CL and Mieap are phase separated in the major phase (electron-dense region in TEM), whereas all CL biosynthesis and remodeling enzymes, including TAMM41, PGS1, PTPMT1, CRLS1, PLA2G6, and TAZ, are predominantly separated in the minor phase (electron-lucent region in TEM). This result suggests that the substrates, intermediates, and products for CL metabolism are not present in the same phase as their catalytic enzymes. Why are the substrates and enzymes not mixed in the same phase of the MLD? We speculate two reasons for this observation. First, since the substrates/intermediates in the MLDs are lipids (oil), the enzymes dissolved in water are not mixed together with lipids (oil). The second reason is "substrate inhibition": if the concentration of the substrate is high, the crowding of the enzyme and substrate inhibits the enzymatic reaction (Reed et al., 2010). Recently, a study demonstrated that sequestration of the enzymes to a membraneless compartment that is away from, but adjacent to, the substrates, can accelerate reactions much faster than when the enzymes are mixed with the substrates (Kojima and Takayama, 2018). This implies that the separation of enzymes from their substrates via LLPS prevents substrate inhibition, which could promote the enzymatic reaction (Kojima and Takayama, 2018). In this case, the interface between the enzyme and substrate phases could be the site of the reaction (Kojima and Takayama, 2018).

In summary, we suggest that MLDs may be the first demonstration of the regulation of CL synthesis and remodeling by membraneless organelles. Possibly, molecular crowding of enzymes 
and substrates and phase separation of them in two distinct phases within the MLDs could accelerate the sequential reactions for CL metabolism by mitigating "substrate inhibition" and maximizing the reactions between oil and water at the interface.

\section{Biosurfactant activity of Mieap is involved in sequential enzymatic reactions for CL metabolism}

In the fat blot assay, we demonstrated that Mieap has a specific affinity to CL but not PC or PE, which are other major components of mitochondrial membranes (Ardail et al., 1990). CL is known to interact with many mitochondrial proteins (Planas-Iglesias et al., 2015); the interaction of CL with its partner is executed by electrostatic and hydrophobic interactions (Gonzalvez and Gottlieb, 2007; Paradies et al., 2014). Our analysis of amino acid sequence data showed that Mieap carries a net positive charge, harboring the clusters of positively charged amino acid residues. In contrast, CL carries a net negative charge (Kaewsuya et al., 2007), while PC and PE do not. In addition, our sequence data show that Mieap contains hydrophobic regions. These facts suggest that Mieap could directly interact with CL via both electrostatic and hydrophobic interactions, indicating that Mieap is a CL-binding protein.

As described, MLDs take the form of multiphase droplets: the major phase containing CL and Mieap and the minor phase (bubbles) containing CL-binding proteins and CL-metabolizing enzymes. According to TEM analysis, these phases correspond to the $\mathrm{OsO}_{4}$-positive (electron-dense) major phase and the $\mathrm{OsO}_{4}$-negative (electron-lucent) minor phase, respectively. The result suggests that Mieap is preferentially located in the same region as CL (oil). We speculate that the multiphase structure of MLDs might be due to a potential surfactant activity of Mieap, which stabilizes the minor phase (water) as fine emulsions (McClements, 2007), reminiscent of water-in-oil emulsions, such as moisturizing cream, which are stabilized with surfactants.

In fact, our sequence analyses of Mieap revealed that, altogether, the N-terminal half is hydrophilic and the C-terminal half is hydrophobic. In addition, the gross halves are separated by the IDRs and the structured regions, inevitably placed in tandem. This amphiphilic tandem is a feature of surfactants. A recent study reported that Ki67 acts as a biological surfactant to disperse mitotic chromosomes, implying that natural proteins can function as surfactants in intracellular compartmentalization if the protein contains an amphiphilic structure (Cuylen et al., 2016). Thus, the multiphase structure of MLDs might be derived from the potential surfactant activity of Mieap, which stabilizes the bubbles as fine emulsions by localizing at two phase boundaries (Figure 7J).

Considering that Mieap at the phase boundaries of MLDs acts as a surfactant, the N-terminal hydrophilic half theoretically faces outward. Our IF data may provide an affirmative suggestion regarding this issue. The anti-FLAG antibody stained the surface of the MLDs induced by N-terminal FLAG-tagged Mieap but not that of the MLDs induced by C-terminal FLAG-tagged Mieap. This indicates that the N-terminal hydrophilic half was exposed to the antibody at the surface of the MLDs.

The morphology of the LDs formed by the Mieap deletion mutants may be consistent with 
our theory regarding the surface activity of Mieap. The multiphase structure was lost in the LDs formed by Mieap deletion mutants that lack a large part of the N-terminal hydrophilic region $(\triangle C C)$ or C-terminal hydrophobic region $(\Delta 275)$. In contrast, the multiphase structure was maintained in the LDs formed by the Mieap deletion mutants that lack the C-terminal hydrophilic end following the hydrophilic-hydrophobic sequence $(\Delta 496)$. One caveat here would be that Mieap not only localizes at phase boundaries potentially as a surfactant but also occupies the major phase with CL because Mieap is a binding partner of CL.

FRAP analysis suggested a unique characteristic of MLDs, different from many canonical LDs: the recovery time of the WT-MLDs was more than $15 \mathrm{~min}$, which is considerably longer than that of canonical LDs (within 1 min). We speculate that this unique feature of MLDs may be due to the limited availability of Mieap in the mitochondria, supporting the fact that MLDs exist and function at the inner mitochondrial membrane within the mitochondria.

In contrast, the recovery time of $\Delta 275 \mathrm{LDs}$ in FRAP was within $60 \mathrm{~s}$, which is similar to canonical LDs, implying that $\triangle 275$ LDs exhibit liquid-like properties and exist outside the mitochondria. The mutant $\Delta 275$ lacks a large part of the C-terminal region, including the hydrophobic structured region and a large part of two clusters of positively charged amino acids, predicting that the ability of Mieap to interact with CL is severely impaired. Consistently, imaging analysis indicated that $\Delta 275 \mathrm{LDs}$ exist apart from the mitochondria.

On the other hand, the mutant $\triangle \mathrm{CC}$ lacks the $\mathrm{N}$-terminal multivalent region, including two CC domains and a large part of the IDRs, predicting that the $\triangle \mathrm{CC}$ mutant lacks the multivalency of $\mathrm{N}$-terminal IDRs but retains the ability to interact with $\mathrm{CL}$ via the structured region. FRAP analysis indicated that $\triangle \mathrm{CC}$ LDs lose their liquid-like properties but gain solid-like characteristics. Consistently, imaging analysis indicated that $\triangle \mathrm{CC}$ LDs exist near the mitochondria but do not exhibit a spherical shape.

In summary, Mieap may serve as a biosurfactant protein and a binding protein for CL. Both the biosurfactant activity of Mieap and its binding to CL could be critical for the MLDs formation in mitochondria. Moreover, we suggest a following model for the sequential CL-metabolizing reactions exerted by Mieap (Figures 7J-7L). Mieap may strongly interact with the substrate (PA) via its C-terminal hydrophobic structured region, which exhibits a specific and stable interaction. On the other hand, Mieap weakly and transiently interacts with a set of CL-metabolizing enzymes via its N-terminal hydrophilic region, which exhibits a multivalent interaction. In this model, once Mieap grabs the substrate via its C-terminal region, Mieap enables the sequential enzymatic reactions of $\mathrm{CL}$ metabolism by transiently interacting with the enzyme corresponding to the substrate, and then just changing the enzymes until mature $\mathrm{CL}$ is produced (Figures $7 \mathrm{~K}$ and $7 \mathrm{~L}$ ). Finally, mature $\mathrm{CL}$ is released from the C-terminal region of Mieap (Figures $7 \mathrm{~K}$ and $7 \mathrm{~L}$ ). Molecular crowding within the MLDs, phase separation of enzymes and substrates in two distinct phases, the interface as a place for the reaction, and the biosurfactant activity of Mieap could probably make the efficient sequential enzymatic reactions for CL metabolism possible. Further investigation of this hypothesis must be required. 


\section{Mieap plays a role in mitochondrial quality control via regulating CL metabolism}

The CL biosynthetic pathway is evolutionarily conserved from yeast to humans, suggesting its essential role in mitochondrial structure and function across species. Disruption at various points in the pathway leads to abnormal phenotypes due to mitochondrial dysfunction (Ren et al., 2014). Especially, mammals suffer embryonic lethality without CL synthase (Kasahara et al., 2019). Among the CL metabolism enzymes in the pathway, TAZ is the only enzyme responsible for human disease, Barth syndrome. Barth syndrome is caused by mutations in the TAZ gene encoding the Tafazzin protein (Ghosh et al., 2019). The clinical symptoms of patients with Barth syndrome include cardiomyopathy, skeletal myopathy with muscle wasting, cyclical neutropenia, and growth delay (Ghosh et al., 2019). All these phenotypes imply that the enzymes involved in the CL metabolic pathway are essential for mitochondrial function. However, the regulation of this pathway has not been elucidated.

We suggest that the MLDs could be the regulatory mechanism for CL metabolic pathway. In the present study, the Mieap-deficient LS174T cells exhibited altered CL metabolism (Figures 5C and 5D), decreased respiration activity, increased ROS levels, and abnormal cristae structure (Figures 7A-7D, and S6A), all of which are consistent with the typical phenotypes induced by CL alteration. Moreover, we confirmed that the Mieap-deficient mice exhibited a decreased number of cristae and a morphological abnormality of the cristae structure in the mitochondria of the kidney and liver tissues (Figures 7E-7H). Furthermore, long-term observation of the Mieap ${ }^{+/+}$Mieap $^{+/}$, and Mieap ${ }^{-1-}$ mice clarified an obesity-related trend in the Mieap-deficient mice (Figures 7I, S6B and $\mathrm{S} 6 \mathrm{C}$ ), which is also attributed to mitochondrial dysfunction. All these phenotypes reflect CL-related mitochondrial dysfunctions; however, they are not as severe as those due to enzyme deficiency, implying that MLDs are not essential in CL biosynthesis and remodeling pathways. MLDs may play a role in mitochondrial quality control through maintaining homeostasis of the inner mitochondrial membrane by regulating CL metabolism, stabilizing oxidative phosphorylation, and suppressing mitochondrial ROS generation. Considering the role of Mieap in p53 function, we suggest that MLDs could function as a spatiotemporal and dynamic regulator/modulator in CL biosynthesis and remodeling of enzymatic reactions to maintain mitochondrial homeostasis by controlling CL integrity under subcellular circumstances and/or in response to cellular stresses.

Consistent with this idea, we reported that although Mieap-deficient mice did not suffer from intestinal dysfunction, Mieap-deficient $\mathrm{Apc}^{\mathrm{Min} /+}$ mice exhibited a remarkable promotion of intestinal tumor generation and malignant transformation, compared to Mieap-WT Apc ${ }^{\mathrm{Min} /+}$ mice (Tsuneki et al., 2015). Furthermore, the mitochondria in the Mieap-deficient tumors revealed abnormal morphology, including fewer cristae and enlarged and spherical shaped mitochondria (Tsuneki et al., 2015). These results support the role of MLDs in mitochondrial quality control through the control of CL metabolism, particularly, in response to oncogenic stress. In addition to $\mathrm{Apc}^{\mathrm{Min} /+}$ mice, we observed a similar effect in a Mieap-deficient gastric cancer mouse model (unpublished data), using the K19-Wnt1/C2mE transgenic mice (Oshima et al., 2006). Therefore, 
the MLD machinery in mitochondrial quality control could play an important role in tumor suppression by regulating CL metabolism, which could be a critical function of tumor suppressor p53.

A significant amount of evidence is now emerging, suggesting a critical role of Mieap in mitochondrial quality control in response to cellular stresses. Under hypoxic conditions, Mieap-deficient gastric cancer cells exhibit abnormal mitochondrial structure and enhanced migration and invasion activities via increased mitochondrial ROS generation (Okuyama et al., 2019). Mieap expression is defective in oncocytic cell tumors of the thyroid, suggesting a causative role in the accumulation of abnormal mitochondria in the tumor cell (Mussazhanova et al., 2020). Oncocytic tumors are characterized by the accumulation of abnormal mitochondria within tumor cells; however, the underlying mechanism remains unclear. Recently, Mieap/Spata18 was shown to play a critical role in DNA-damage-induced mitophagy (Dan et al., 2020). The results reported in these studies are largely consistent with our previous observations (Miyamoto et al., 2011; Kitamura et al., 2011). However, all the observations from these studies, as well as our previous studies, could be explained by the idea that MLDs play a role in mitochondrial quality control via regulating CL metabolism. The only unaddressed question is whether lysosome/lysosomal proteins are involved in the function of MLDs (Miyamoto et al., 2011; Kitamura et al., 2011; Nakamura et al., 2012; Miyamoto et al., 2012). Although this point is an important challenge for the future, we strongly suggest that the mechanism underlying these observations is executed by the MLDs as a machinery in mitochondrial quality control.

Currently, we have unable to visualize MLD structures in cells and tissues under physiological conditions in the absence of any stress; however, we have already obtained MLD-deficient phenotypes under these conditions, implying that physiological MLDs may be active even in cells under non-stressful conditions without MLD structures. Previously, we only succeeded in observing the MIV structures (equivalent to MLDs) through IF and TEM experiments, which were experimentally induced by the endogenous Mieap protein in cells treated with a high dose of ionizing radiation (IR) (Kitamura et al., 2011). After IR, mitochondrial CL is rapidly and massively oxidized and degraded. Under this situation, we speculate that MLDs may play a role in rapid degradation and transacylation of the oxidized CL for recycling and de novo production of CL (Chao et al., 2018). This could lead to stabilization of mitochondrial function and reduction of mtROS production, resulting in maintenance of whole cell homeostasis, which is compatible with p53 function. The maintenance of mitochondrial integrity by MLDs under stressful conditions may contribute to healthy cell survival via increased mitochondrial ATP production and decreased ROS generation, which plays a critical role in tumor suppression. We speculate that the visualized MLDs demonstrated in this study could mimic physiological MLDs that would exist under physiological conditions.

Regarding MLD structures under the physiological condition, we suggest a possibility that in vivo phase separation of CL metabolic reactions by Mieap may morphologically exhibit a stratiform structure along the lines of the inner mitochondrial membrane via membrane wetting by 
MLDs (Li et al., 2008). Wetting is the ability of a liquid to maintain contact with a solid surface, resulting from intermolecular interactions when the two materials are brought together. The degree of wetting, wettability, is determined by a force balance between adhesive and cohesive forces (Dutschk et al, 2012). In the case of wetting between a liquid and a solid, adhesive, or cohesive forces cause an LD to spread across the surface or ball up and avoid contact with the surface, respectively (De Gennes, 1985; Dutschk et al, 2012). If the interaction strength between the liquid and solid is extremely strong, an LD spreads over a large area of the surface of the solid, becoming nearly flat (De Gennes, 1985; Dutschk et al, 2012). In addition, if there is a surfactant(s) between the two materials, a nonwetting material can be transformed into a wetting substance through reduction in its surface tension by surfactants (Lee et al., 2008; Rosen and Kunjappu, 2012). This theory could be applied to the relationship between the inner mitochondrial membrane and MLDs. Since Mieap may exhibit a very strong affinity and a biosurfactant activity with respect to CL, the physiological MLDs would spread out over the inner mitochondrial membrane by high wettability or perfect wetting, becoming a stratiform structure along the lines of the membrane. We speculate that in vivo phase separation of CL metabolism by Mieap does not induce spherical LDs but rather induces possible layer-structured membraneless organelles at the inner mitochondrial membrane.

A recent study reported that PGS1, PTPMT1, and CRLS1 form a large mitochondrial CL synthesis complex, which revealed a molecular mass of nearly $700-800 \mathrm{kDa}$ in biochemical analysis, in human cells (Serricchio et al., 2018). In addition, this large CL synthesis complex was shown to include multiple CL-binding proteins. These observations are consistent with our results that MLDs contain all CL synthesis enzymes and several CL-binding proteins. However, IF experiments on PGS1 or CRLS1 in that study indicated that the signal from neither PGS1 nor CRLS1 showed MLD-like structures in the mitochondria (Serricchio et al., 2018). Their results are also consistent with our results from the live-cell imaging of EGFP-fused CL synthesis enzymes, including PGS1 and CRLS1, which showed that none of the EGFP-tagged CL synthesis enzymes exhibit the MLD-like structures (Figures S5A-S5F). Therefore, we suggest that, under non-stress conditions, a minute size of MLDs or possible layer-structured membraneless organelles that are phase separated by Mieap may serve to compartmentalize and facilitate CL metabolic reactions in vivo, leading to the maintenance of efficient enzymatic reactions. Further investigation is needed to clarify the real picture of physiological membraneless organelles involved in CL metabolism. 


\section{Acknowledgments}

This work was supported by grants from The National Cancer Center Research and Development

Fund (29-E-1, 30-A-3), JSPS KAKENHI Grant Numbers JP-19K07655, JP-19K07703, JP-17H06267 and JP-20K20305, and The Naito Foundation.

\section{Author contributions}

N.I., K.H., Y.S., Y.N., and H.A. performed experiments. N.I. and H.A. analyzed data. N.I. and H.A. designed the research. N.I. and H.A. wrote paper. H.A. coordinated and supervised the project.

\section{Declaration of interests}

The authors declare no competing interests. 


\section{Figure legends}

\section{Figure 1. Mieap forms liquid droplets}

(A) Time-lapse imaging of the cell expressing EGFP-Mieap. The A549-cont cells were infected with Ad-EGFP-Mieap. Image acquisition was started $10.5 \mathrm{~h}$ after infection of Ad-EGFP-Mieap, and $0.5 \mathrm{~h}$ after MitoTracker Red treatment. See also Video S1.

(B) Comparative imaging of the EGFP-Mieap condensates, visualized by both EGFP-Mieap and immunofluorescence (IF) using anti-Mieap antibody (upper panel) or anti-GFP antibody (lower panel). The A549-cont cells infected with Ad-Mieap were subjected to IF analysis $24 \mathrm{~h}$ after infection.

(C) IF imaging of the N-FLAG-Mieap condensates (upper panel) or C-FLAG-Mieap condentates (lower panel) using anti-FLAG antibody. A549-cont cells infected with Ad-N-FLAG-Mieap or Ad-C-FLAG-Mieap were subjected to IF analysis $27 \mathrm{~h}$ after infection. The images were acquired under the same detection condition (excitation, $561 \mathrm{~nm}$; detection wave lengths, 570-670 nm; Laser transmissivity, $0.1 \%$, photomultiplier tube voltage, $465 \mathrm{~V}$ ).

(D) Transmission electron microscopy of the Mieap condensates stained with osmium $\left(\mathrm{OsO}_{4}\right)$. The A549-cont cells infected with Ad-Mieap were subjected to analysis on day 1 after infection.

(E) Post-embedding immunoelectron microscopy of the Mieap condensates using anti-Mieap antibody. The A549-cont cells infected with Ad-Mieap were subjected to analysis on day 1 after infection.

(F) Time-lapse imaging of the self-fusing EGFP-Mieap condensates in the A549-cont cell. The fusing portion is indicated by yellow arrows. See also Video S2.

\section{Figure 2. Mieap is an IDR-containing protein that has a potential to drive LLPS}

(A) Sequence analyses of Mieap protein. VL3-BA, prediction of the IDRs on amino acid sequence of Mieap, in which the bold lines indicate the IDRs (Uversky et al., 2007); DisMeta, meta-prediction of the IDRs on amino acid sequence of Mieap (Huang et al., 2014); COILS; the coiled-coil regions annotated on the amino acid sequence of Mieap over 21 residue windows (Lupas et al., 1991); Hydro, the hydrophobicity of Mieap over 9 residue windows (Kyte and Doolittle, 1982); NCPR, the linear net charge per residue of Mieap over 5 residue windows (Holehouse et al., 2017).

(B) Schematic of the domain structure of Mieap. The dashed vertical line indicates the boundary of the gross hydrophilic and hydrophobic halves, separated by the IDR3 and the adjacent structured region. The asterisks indicate the clusters of positively charged residues.

(C) EGFP-Mieap and the three deletion-mutant forms. Adenoviral vectors harboring the deletion mutants of Mieap lacking coiled-coil domains together with the intervening IDR2 and a part of the adjacent IDR1 and IDR3 ( $\triangle \mathrm{CC}), \mathrm{C}$-terminal side next to the coiled-coil domains $(\Delta 275)$, and the C-terminal IDR4 $(\Delta 496)$ were prepared as indicated. The numbers indicate amino acid numbers.

(D) Representative images with cross-sectional slice view of the liquid droplets (LDs) formed by EGFP-Mieap and the three deletion mutants $(\triangle \mathrm{CC}, \Delta 275$, and $\Delta 496)$ in the A549-cont cells 
obtained by fluorescent confocal microscopy. The cells were infected with Ad-EGFP-Mieap, Ad-EGFP-Mieap $\Delta$ CC, Ad-EGFP-Mieap $\Delta 275$, and Ad-EGFP-Mieap $\Delta 496$, respectively. See also Video S3.

(E) Subcellular localization of the LDs formed by EGFP-Mieap and the three deletion mutants ( $\triangle \mathrm{CC}, \Delta 275$, and $\Delta 496$ ) contrasted with a mitochondrial probe, MitoTracker Red. The A549-cont cells were infected as in (D), subsequently treated with MitoTracker Red for 20 min, and imaged by fluorescent confocal microscopy. See also Video S3.

\section{Figure 3. Availability of Mieap is limited in MLDs}

(A) Representative fluorescence recovery after photobleaching (FRAP) images of condensates formed by EGFP-Mieap and the three deletion mutants $(\triangle \mathrm{CC}, \Delta 275$, and $\Delta 496)$ in the A549-cont cells. Each condensate was subjected to spot-bleach using a $488 \mathrm{~nm}$ laser at $10 \%$ laser power with $11.6 \mu \mathrm{s} / \mu \mathrm{m}$ exposure time and followed up for $60 \mathrm{~s}$. The bleached areas are indicated by yellow arrows. Scale bar, $2 \mu \mathrm{m}$.

(B) Plotting of the normalized average fluorescence recovery in the FRAP experiment as in (A). $\mathrm{n}=$ 15 condensates for each construct. Data shown are mean \pm SD.

(C) Plotting of the normalized average fluorescence recovery in the FRAP experiment with weaker laser exposure; laser power was weakened to $1.4 \%$ and the exposure time was shortened to 1.4 $\mu \mathrm{s} / \mu \mathrm{m} . \mathrm{n}=15$ condensates for each construct. Data shown are mean $\pm \mathrm{SD}$.

(D) Plotting of the normalized average fluorescence recovery in the long-term FRAP experiment; observation duration was expanded to 15 minutes after photobleaching the entire condensates using a $488 \mathrm{~nm}$ laser at $1.4 \%$ laser power with $1.4 \mu \mathrm{sec} / \mu \mathrm{m}$ exposure time. $\mathrm{n}=10$ condensates for each construct. Data shown are mean $\pm \mathrm{SD}$.

\section{Figure 4. MLDs exist in the mitochondria and phase separate mitochondrial phospholipid cardiolipin}

(A) Live-cell imaging and the 3D reconstruction showing the spatial relationship between the MLDs (EGFP-Mieap) and the mitochondrial outer membranes visualized with mApple-TOMM20. The A549-cont cells were co-infected with Ad-EGFP-Mieap and Ad-mApple-TOMM20. Left: a cell image. Middle: higher magnification of the area indicated by the dashed square on the left panel and line-scan of fluorescence intensities along the dashed arrow. Right: 3D reconstruction of the cell shown in the left panel. See also Video S4 and Figure S2. A representative image is shown (A-C, E-G).

(B) Live-cell imaging showing the spatial relationship between the enlarged MLDs and the mitochondrial outer membranes. The A549-cont cells were co-infected with Ad-Mieap, Ad-EGFP-Mieap, and Ad-mApple-TOMM20. Lower right: line-scan as in (A). See also Video S4

(C) Live-cell imaging showing phase separation of CL by MLDs. CL was visualized by 10-nonylacridine orange bromide (NAO). The A549-cont cells were infected with Ad-Mieap and 
Ad-TagRFP-T-Mieap, and subsequently treated with 10-nonylacridine orange bromide (NAO) (200 $\mathrm{nM})$. Lower right: line-scan as in (A). See also Video S6.

(D) Lipid-binding analysis of GST-tagged Mieap protein. GST-Mieap or GST was incubated with the membranes on which increasing amounts of CL, phosphatidylcholine (PC), and phosphatidylethanolamine (PE) ranging from 0-667 pmol were spotted. The protein-lipid interactions were visualized using an anti-Mieap antibody and/or anti-GST antibody as indicated.

(E-G) Live-cell imaging showing phase separation of EGFP-cytochrome $c$ (E), EGFP- ATP5F1B (F), and EGFP- PHB2 (G) by MLDs. The A549-cont cells were infected with Ad-EGFP-cytochrome $c$, and subsequently infected with Ad-Mieap and Ad-TagRFP-T-Mieap (E). The A549-cont cells were transfected with pEGFP-ATP5F1B (G) and pEGFP-PHB2 (H), and subsequently infected with Ad-Mieap and Ad-TagRFP-T-Mieap (F, G). Lower right: line-scan as in (A). See also Video S6.

\section{Figure 5. Mieap is involved in CL Metabolism}

(A) Quantitative assessment of total CL, comparing the A549 cells with (Ad-Mieap) and without (Non-infection) exogenous Mieap expression. The A549 cells $24 \mathrm{~h}$ after infection with Ad-Mieap were harvested, and compared with non-infected cells by mass spectrometric analysis. Duplicate experiments were performed. Data shown are mean \pm SD.

(B) Comparison of CL species between the A549 cells described in (A). Absolute values of selected CL species were shown as amount of substance per cell (left panel). Relative values of selected CL species were shown as \% of total CL (right panel). Data shown are mean \pm SD.

(C) Quantitative assessment of total CL, comparing the LS174T cells with (Cont) and without (Mieap-KD) endogeneous Mieap expression. The LS174T-cont and Mieap-KD cells incubated under a normal condition were harvested and subjected to mass spectrometric analysis. Duplicate experiments were performed. Data shown are mean \pm SD.

(D) Comparison of CL species between the LS174T cells described in (C). Absolute values of selected CL species were shown as amount of substance per cell (left panel). Relative values of selected CL species were shown as \% of total CL (right panel). Data shown are mean \pm SD.

See also Table $\mathrm{S} 1$.

\section{Figure 6. MLDs compartmentalize CL metabolic reactions}

(A) Scheme of the conventional CL metabolic pathway. Abbreviations: PA, phosphatidic acid; CDP-DG: cytidine diphosphate diacylglycerol; PGP, phosphatidylglycerophosphate; PG, phosphatidylglycerol; $\mathrm{CL}_{\mathrm{N}}$, nascent cardiolipin; $\mathrm{CL}_{\mathrm{M}}$, mature cardiolipin.

(B-J) Live-cell imaging evaluating involvement of (B) TAMM41, (C) PGS1, (D) PTPMT1, (E) CRLS1, (F) PLA2G6, (G) TAZ, (H) PRELI, (I) LONP1, and (J) PLD6 in phase separation by MLDs. The A549-cont cells were transfected with (B) pEGFP-TAMM41, (C) pEGFP-PGS1, (D) pEGFP-PTPMT1, (E) pEGFP-CRLS1, (F) pEGFP-PLA2G6, (G) pEGFP-TAZ, (H) pEGFP-PRELI, (I) pEGFP-LONP1, and (J) pEGFP-PLD6 subsequently infected with Ad-Mieap and 
Ad-TagRFP-T-Mieap. Lower right: line-scan of fluorescence intensities along the dashed arrow. See also Video S7.

\section{Figure 7. Possible role of Mieap in mitochondrial quality control via regulating CL metabolism}

(A) Oxygen consumption rates (OCR) of LS174T-cont and Mieap-KD cells under a normal condition calculated with a flux analyzer. Data are shown as mean \pm SD $(n=9)$. Statistics were assessed using Student's two-tailed t-test $(\mathrm{p}<0.01)$.

(B) ATP production rates of LS174T-cont and Mieap-KD cells under a normal condition calculated with a flux analyzer, using Seahorse XF real-time ATP rate assay. The blue bar indicates the mitochondrial ATP production rate. The red bar indicates glycolytic ATP production rate. Data are shown as mean \pm SD. Statistics were assessed using Student's two-tailed t-test $(\mathrm{p}<0.01)$.

(C) Morphology of the mitochondria of LS174T-cont and Mieap-KD cells in transmission electron microscopy (TEM).

(D) The ratio of the cristae area per mitochondrial section of LS174T-cont and Mieap-KD cells. The quantitative data were obtained from the TEM images as in (C), and displayed in violin plot. $\mathrm{n}=$ 197 mitochondria (WT) and 329 mitochondria (Mieap-KO) collected from 10 cells, respectively. Statistics were assessed using Student's two-tailed t-test $(\mathrm{p}<0.0001)$.

(E) Morphology of the kidney mitochondria of Mieap ${ }^{+/+}$(WT) and Mieap ${ }^{-/-}$(Mieap-KO) mice in TEM.

(F) The ratio of the cristae area per mitochondrial section of the WT and Mieap-KO mice kidneys. The quantitative data were obtained from the TEM images as in (D), and displayed in violin plot. $\mathrm{n}$ $=190$ mitochondria (WT) and 234 mitochondria (Mieap-KO). Statistics were assessed using Student's two-tailed t-test $(\mathrm{p}<0.0001)$.

(G) Morphology of the liver mitochondria of the WT and Mieap-KO mice in TEM.

(H) The ratio of the cristae area per mitochondrial section of the WT and Mieap-KO mice livers. The quantitative data were obtained from the TEM images as in $(\mathrm{G})$, and displayed in violin plot. $\mathrm{n}$ = 146 mitochondria (WT) and 134 mitochondria (Mieap-KO). Statistics were assessed using Student's two-tailed t-test $(\mathrm{p}<0.0001)$.

(I) Body weights of Mieap ${ }^{+/+}$, Mieap $^{+/-}$, and Mieap ${ }^{-/-}$mice. A total of 1353 mice $\left(\mathrm{n}=364\right.$ Mieap $^{+/+}$, $656 \mathrm{Mieap}^{+/-}$, and $333 \mathrm{Mieap}^{-/-}$mice, 7-130 weeks of age) were cross-sectionally weighed. Dots and quadratic regression curves with $95 \%$ confidence intervals were shown for each genotype.

(J) Hypothetical model for biosurfactant activity of Mieap. In the electron-dense major phase (lipid phase) (colored in black), Mieap (colored in green) exists both as a CL-binding "scaffold" protein and as a potential "biosurfactant". At the boundary between the outside of the MLDs (water phase) and the electron-dense major phase (lipid phase) or between the electron-dense major phase (lipid phase) and electron-lucent minor phases (water phase), the hydrophilic N-terminal side of Mieap always face water phase at the boundary. 
$(\mathrm{K}, \mathrm{L})$ Hypothetical model for Mieap-mediated sequential enzymatic reactions in CL metabolism. Black areas indicate lipid phase containing CL and Mieap. Gray areas indicate water phase containing enzymes. The sequential reactions occur at the interface between the outside of the MLDs (water phase) and the major phase (lipid phase) (K) or between the major phase (lipid phase) and the minor phases (water phase) (L). Once Mieap (green) stably interacts with PA via the C-terminal region, one of the enzymes transiently and weakly interacts with the N-terminal region of Mieap. When Mieap interacts with TAMM41, PA is converted to CDP-DG. Such a reaction between each enzyme and the corresponding substrate could be repeated until mature CL is produced. Molecular crowding of enzymes and substrates within and/or peripheral of the MLDs, phase separation of enzymes and substrates into two distinct phases, multivalent interaction of Mieap with enzymes, and the biosurfactant activity of Mieap may enable the efficient sequential reactions for CL metabolism. Abbreviations: PA, phosphatidic acid; CDP-DG: cytidine diphosphate diacylglycerol; PGP, phosphatidylglycerophosphate; PG, phosphatidylglycerol; CL $_{\mathrm{OX}}$, oxidized cardiolipin; $\mathrm{CL}_{\mathrm{N}}$, nascent cardiolipin; $\mathrm{CL}_{\mathrm{M}}$, mature cardiolipin. 


\section{Materials and methods}

\section{Cell lines}

The following cell lines were purchased from the American Type Culture Collection: A549 (tissue, lung cancer; gender, male), LS174T (tissue, colon cancer; gender, female), and 293 (tissue, embryonic kidney). A549 cells were cultured in RPMI 1640 (Sigma). LS174T and 293 cells were cultured in DMEM (Sigma). All the media were supplemented with $10 \%$ fetal bovine serum. Cells were maintained at $37^{\circ} \mathrm{C}$ in a humidified chamber with $5 \% \mathrm{CO}_{2}$. The cell lines have not been authenticated.

\section{Mice}

The animal experiment protocols were approved by the Committee for Ethics in Animal Experimentation (approved protocol No. T17-043), and the experiments were conducted in accordance with the Guideline for Animal Experiments of the National Cancer Center. C57BL/6J WT mice were obtained from CLEA Japan (Tokyo, Japan). The Mieap-knockout (Mieap ${ }^{-/}$) mice were generated by using the Cre/loxP recombination system as previously reported (Tsuneki et al., 2015). Briefly, the floxed and trapped alleles were generated using a single construct bearing a gene-trap cassette doubly flanked by LoxP and FRT located between exons 5 and 8 of the mouse Mieap gene, which is located on chromosome 5. The Mieap homozygous (Mieap ${ }^{-/}$) deficient mice were generated by mating between bleeding pairs of the Mieap heterozygous (Mieap ${ }^{+-}$) mice. All mice were housed at $22 \pm 2^{\circ} \mathrm{C}$ with a $12 \mathrm{~h} \mathrm{light/dark} \mathrm{cycle} \mathrm{with} \mathrm{free} \mathrm{access} \mathrm{to} \mathrm{food,} \mathrm{CE-2} \mathrm{(CLEA}$ Japan) and water.

\section{Establishment of KD cell lines}

We established a Mieap-KD cell line using LS174T, as previously described (Miyamoto et al., 2011). Mieap expression was inhibited in the cell line by retroviral expression of short-hairpin RNA (shRNA) against the Mieap sequence. We also established LS174T-cont cells applied to experiments in Figure 5 and S6 using the retroviral vector with target sequence for EGFP, LS174T-cont cells applied to experiments in Figure 7 using an empty retroviral vector, and A549-cont cells using an empty retroviral vector.

\section{Plasmid construction}

\section{Constructs containing Mieap}

For construction of the plasmid containing N-terminal EGFP-tagged Mieap, the nucleotide sequence of the Mieap was PCR-amplified using the primers (N-EGFP-Mieap-F and N-EGFP-Mieap-R). The PCR products were digested with Kpn I, and ligated into pEGFP-C1 (Clontech) cut with the same enzyme. For construction of the plasmid containing C-terminal EGFP-tagged Mieap, the nucleotide sequence of Mieap excluding stop codon was PCR-amplified using the primers (C-EGFP-Mieap-F and C-EGFP-Mieap-R). The PCR products were ligated into pCR-Blunt II-TOPO vector (Thermo Fisher Scientific) and sequenced. The inserted products were 
excised using the Hind III restriction sites, and ligated into pEGFP-N1 (Clontech) cut with the same enzyme. The N-terminal EGFP-tagged Mieap was used as EGFP-Mieap except for Figure 4A, 4B, S2, and Video S4, where the C-terminal EGFP-tagged Mieap was used.

The plasmid containing N-FLAG-Mieap (pN-FLAG-Mieap) was constructed as follows. The nucleotide sequence of Mieap was PCR-amplified using the primers (N-FLAG-Mieap-F and N-FLAG-Mieap-R). The PCR products were ligated into pCR-Blunt II-TOPO vector (Thermo Fisher Scientific) and sequenced. The inserted products were excised using the Kpn I restriction sites, and ligated into the pre-digested pcDNA3.1 (+) (Thermo Fisher Scientific) cut with the same enzyme. The nucleotide sequence of Mieap was excised from the plasmid using the Hind III and Xho I restriction sites, and ligated into the pre-digested pCMV-Tag2A (Agilent) cut with the same enzyme.

The plasmid containing C-FLAG-Mieap (pC-FLAG-Mieap) was constructed as follows. The nucleotide sequence of Mieap excluding stop codon was PCR-amplified using the primers (C-EGFP-Mieap-F and C-EGFP-Mieap-R), the same primers used for construction of the plasmid containing C-terminal EGFP-tagged Mieap. The PCR products were ligated into pCR-Blunt II-TOPO vector (Thermo Fisher Scientific) and sequenced. The inserted products were excised using the Hind III restriction site, and ligated into the pre-digested p3xFLAG-CMV-14 (Sigma Aldrich) cut with the same enzyme.

Prior to construction of the plasmid containing EGFP-Mieap deletion mutants, point mutations in Bgl II, Sac I, EcoR I, and Pst I restriction sites of the multiple cloning site of pEGFP-Mieap were introduced using the QuikChange Site-Directed Mutagenesis Kit (Agilent) with primers Mut-F1, Mut-R1, Mut-F2 and Mut-R2, which was confirmed by DNA sequencing.

For construction of the plasmid containing EGFP-Mieap $\Delta C C$ (pEGFP-Mieap $\Delta C C$ ), the nucleotide sequence of pEGFP-Mieap between two Pst I restriction sites was deleted by digestion using Pst I. The remainder was self-ligated, additionally deleting c.810C using the QuikChange Site-Directed Mutagenesis Kit (Agilent) with primers Mut-F3 and Mut-R3 to make the deletion mutation in-frame.

For construction of the plasmid containing EGFP-Mieap $\Delta 275$ (pEGFP-Mieap $\Delta 275$ ), the nucleotide sequence of pEGFP-Mieap between the Bgl II and Sma I restriction site was deleted by digestion using Bgl II and Sma I. After blunting with T4 DNA polymerase (Thermo Fisher Scientific), the remainder was self-ligated.

For construction of the plasmid containing EGFP-Mieap $\Delta 496$ (pEGFP-Mieap $\Delta 496$ ), the nucleotide sequence of pEGFP-Mieap between the EcoR I and Kpn I restriction site was deleted by digestion using EcoR I and Kpn I. After blunting with T4 DNA polymerase (Thermo Fisher Scientific), The remainder was self-ligated.

For construction of the plasmid containing TagRFP-T-Mieap (pTagRFP-T-Mieap), the nucleotide sequence of pEGFP-Mieap between the Nhe I and Xho I restriction site containing EGFP was replaced with nucleotide sequence of pTagRFP-T-EEA1 (Addgene \#42635) between the Nhe I and Xho I restriction site containing TagRFP-T, by digestion using Nhe I and Xho I. 
For construction of the plasmid containing GST-Mieap (pGST-Mieap), the nucleotide sequence of the Mieap (amino acids 99-298) was PCR-amplified using the primers (GST-Mieap-F and GST-Mieap-R). The PCR products were ligated into pCR-Blunt II-TOPO vector (Thermo Fisher Scientific) and sequenced. The products were digested with EcoR I and Xho I, and ligated into pGEX5X-2 (Cytiva).

\section{Other constructs}

For construction of the plasmid containing EGFP-BNIP3 (pEGFP-BNIP3), plasmid containing FLAG-BNIP3 (pCMV-Tag2B-BNIP3) was constructed in advance. For construction of the pCMV-Tag2B-BNIP3, the nucleotide sequence of BNIP3 was PCR-amplified using the primers (BNIP3-F and BNIP3-R). The PCR products were ligated into pCR-Blunt II-TOPO vector (Thermo Fisher Scientific) and sequenced. The inserted products were digested with EcoR I and Xho I, and ligated into the pre-digested pCMV-Tag2B (Agilent) cut with the same enzyme. The nucleotide sequence of pCMV-Tag2B-BNIP3 was digested at the EcoR I and Xho I restriction site, which was subsequently blunted with T4 DNA polymerase (Thermo Fisher Scientific). pEGFP-C1 (Clontech) was digested with Bgl II, blunted with T4 DNA polymerase, self-ligated, digested with EcoR I and Sma I, and ligated with the fragment of the pCMV-Tag2B-BNIP3.

For construction of the plasmid containing EGFP-NIX (pEGFP-NIX), plasmid containing FLAG-NIX (pCMV-Tag2B-NIX) was constructed in advance. For construction of the pCMV-Tag2B-NIX, the nucleotide sequence of NIX was PCR-amplified using the primers (NIX-F and NIX-R). The PCR products were ligated into pCR-Blunt II-TOPO vector (Thermo Fisher Scientific) and sequenced. The inserted products were digested with EcoR I and Xho I, and ligated into the pre-digested pCMV-Tag2B (Agilent) cut with the same enzyme. The nucleotide sequence of pCMV-Tag2B-NIX was digested at the EcoR I and Xho I restriction site, which was subsequently blunted with T4 DNA polymerase (Thermo Fisher Scientific). pEGFP-C1 (Clontech) was digested with Bgl II, blunted with T4 DNA polymerase, self-ligated, digested with EcoR I and Sma I, and ligated with the fragment of the pCMV-Tag2B-NIX.

The plasmid containing EGFP-cytochrome $c$ (pEGFP-cytochrome $c$ ) was constructed as follows. The nucleotide sequence of cytochrome $c$ was PCR-amplified using the primers (Cytochrome $c-\mathrm{F}$ and Cytochrome $c-\mathrm{R}$ ) as previously reported elsewhere (Goldstein et al., 2000). The PCR products were ligated into pCR-Blunt II-TOPO vector (Thermo Fisher Scientific) and sequenced. The inserted products were excised using the EcoR I and BamH I restriction sites, and ligated into the pEGFP-C1 (Clontech) cut with the same enzymes.

For construction of the plasmid backbone containing EGFP (pN-EGFP), the nucleotide sequence of EGFP excluding stop codon was PCR-amplified using the primers (N-EGFP-F and N-EGFP-R). The PCR products were digested with Hind III and BamH I, and ligated into pcDNA3.1 (+) (Thermo Fisher Scientific) cut with the same enzymes.

For construction of the plasmid backbone containing EGFP (pC-EGFP), the nucleotide sequence of EGFP was PCR-amplified using the primers (C-EGFP-F and C-EGFP-R). The PCR 
products were digested with BamH I and Not I, and ligated into pcDNA3.1 (+) (Thermo Fisher Scientific) cut with the same enzymes.

For construction of the plasmid containing EGFP-ATP5F1B (pEGFP-ATP5F1B), the nucleotide sequence of ATP5F1B excluding stop codon was PCR-amplified using the primers (ATP5F1B-F1, ATP5F1B-R1, ATP5F1B-F2, and ATP5F1B-R2). The PCR products were digested with Hind III and BamH I, and ligated into pC-EGFP cut with the same enzymes.

For construction of the plasmid containing EGFP-PHB2 (pEGFP-PHB2), the nucleotide sequence of PHB2 excluding stop codon was PCR-amplified using the primers (PHB2-F and PHB2-R). The PCR products were digested with Nhe I and Kpn I, and ligated into pC-EGFP cut with the same enzymes.

For construction of the plasmid containing EGFP-TAMM41 (pEGFP-TAMM41), the nucleotide sequence of TAMM41 excluding stop codon was PCR-amplified using the primers (TAMM41-F and TAMM41-R). The PCR products were digested with Nhe I and BamH I, and ligated into pC-EGFP cut with the same enzymes.

For construction of the plasmid containing EGFP-PGS1 (pEGFP-PGS1), the nucleotide sequence of PGS1 excluding stop codon was PCR-amplified using the primers (PGS1-F and PGS1-R). The PCR products were digested with Hind III and BamH I, and ligated into pC-EGFP cut with the same enzymes.

For construction of the plasmid containing EGFP-PTPMT1 (pEGFP-PTPMT1), the nucleotide sequence of PTPMT1 excluding stop codon was PCR-amplified using the primers (PTPMT1-F and PTPMT1-R). The PCR products were digested with Nhe I and Hind III, and ligated into $\mathrm{pC}$-EGFP cut with the same enzymes.

For construction of the plasmid containing EGFP-CRLS1 (pEGFP-CRLS1), the nucleotide sequence of CRLS1 was PCR-amplified using the primers (CRLS1-F and CRLS1-R). The PCR products were digested with BamH I and Not I, and ligated into pN-EGFP cut with the same enzymes.

For construction of the plasmid containing EGFP-PLA2G6 (pEGFP-PLA2G6), the nucleotide sequence of PLA2G6 excluding stop codon was PCR-amplified using the primers (PLA2G6-F and PLA2G6-R). The PCR products were digested with Nhe I and Kpn I, and ligated into pC-EGFP cut with the same enzymes.

For construction of the plasmid containing EGFP-TAZ (pEGFP-TAZ), the nucleotide sequence of TAZ excluding stop codon was PCR-amplified using the primers (TAZ-F and TAZ-R). The PCR products were digested with Nhe I and Kpn I, and ligated into pC-EGFP cut with the same enzymes.

For construction of the plasmid containing EGFP-PRELI (pEGFP-PRELI), the nucleotide sequence of PRELI excluding stop codon was PCR-amplified using the primers (PRELI-F and PRELI-R). The PCR products were digested with Nhe I and BamH I, and ligated into pC-EGFP cut with the same enzymes. 
For construction of the plasmid containing EGFP-LONP1 (pEGFP-LONP1), the nucleotide sequence of LONP1 excluding stop codon was PCR-amplified using the primers (LONP1-F and LONP1-R). The PCR products were digested with Hind III and BamH I, and ligated into pC-EGFP cut with the same enzymes.

For construction of the plasmid containing EGFP-PLD6 (pEGFP-PLD6), the nucleotide sequence of PLD6 excluding stop codon was PCR-amplified using the primers (PLD6-F and PLD6-R). The PCR products were digested with Nhe I and Kpn I, and ligated into pC-EGFP cut with the same enzymes.

\section{Transfection}

For transfection, cells were seeded $\left(2 \times 10^{5}\right.$ cells/dish) in $35 \mathrm{~mm}$ glass bottom dish. The plasmids (2 $\mu \mathrm{g} /$ dish) were transfected using FuGENE6 transfection reagent (Promega), according to the manufacturer's instructions.

\section{Recombinant adenovirus construction}

Ad-Mieap was derived from the viruses previously reported (Miyamoto et al., 2011; Nakamura et al., 2012; Kitamura et al., 2011). Replication-deficient recombinant viruses Ad-EGFP-Mieap, Ad-N-FLAG-Mieap, Ad-C-FLAG-Mieap, Ad-EGFP-Mieap $\Delta C C \quad$ ( 1 104-270), Ad-EGFP-Mieap $\Delta 275, \quad$ Ad-EGFP-Mieap $\Delta 496$, Ad-TagRFP-T-Mieap, Ad-mApple-TOMM20 derived from mApple-TOMM20-N-10 (Addgene \#54955), Ad-EGFP-BNIP3, Ad-EGFP-NIX, Ad-AcGFP1-Mito, Ad-DsRed2-Mito, and Ad-EGFP-cytochrome $c$ were generated from the corresponding plasmid vectors and purified as described previously (Oda et al., 2000). Briefly, the DNA fragments obtained by restriction of each plasmid vector were subjected to blunting using T4 DNA polymerase, ligated into the SmiI site of the cosmid pAxCAwtit (Takara), which contains the CAG promoter and the entire genome of type 5 adenovirus except for E1 and E3 regions. Recombinant adenoviruses were generated by in vitro homologous recombination in the 293 cell line with the cDNAs-inserted pAxCAwtit and the adenovirus DNA terminal-protein complex. Viruses were propagated in the 293 cell line and purified by two rounds of $\mathrm{CsCl}$ density centrifugation. Viral titers were determined by a limiting dilution bioassay using 293 cells.

\section{Adenoviral infection}

Infection of the cell lines was carried out by adding viral solutions to cell monolayers, and incubating at $37^{\circ} \mathrm{C}$ for $120 \mathrm{~min}$ with brief agitation every $20 \mathrm{~min}$. This was followed by the addition of culture medium and the return of the infected cells to the $37^{\circ} \mathrm{C}$ incubator.

\section{Immunocytochemistry}

For immunocytochemistry, cells were grown on eight-well chamber slides $\left(1-4 \times 10^{4}\right.$ cells/well $)$ at $37^{\circ} \mathrm{C}$ in conventional culture medium, and fixed in paraformaldehyde (Figure 1B, 2\%; Figure 1C, 4\%) for $15 \mathrm{~min}$ at room temperature. The slides were incubated with Triton X-100 (Figure 1B, 
$0.1 \%$ for $2 \mathrm{~min}$; Figure $1 \mathrm{C}, 0.5 \%$ for $10 \mathrm{~min}$ ), and washed three times with phosphate buffered saline (PBS) at room temperature. Cells were blocked with $3 \%$ bovine serum albumin (BSA) in PBS (Figure 1B, for $3 \mathrm{~h}$; Figure 1C, for $2 \mathrm{~h}$ ), and sequentially incubated with rabbit polyclonal anti-Mieap antibody (1:200), mouse monoclonal anti-GFP antibody (1:200), or mouse monoclonal anti-FLAG antibody $(1: 1000)$ for $2 \mathrm{~h}$ at room temperature. After washing three times with PBS, the slides were incubated with Alexa Fluor 546 goat anti-rabbit IgG antibody (1:200) or Alexa Fluor 546 goat anti-mouse IgG antibody (1:200) at room temperature (Figure 1B, for 2 h; Figure 1C, for 1 h). The slides were washed three times with PBS. The slides were mounted with VECTASHIELD H-1000 (Vector Laboratories), and observed using a FLUOVIEW FV3000 confocal laser scanning microscope (Olympus).

\section{Transmission electron microscopy (TEM)}

The A549-cont cells $\left(4 \times 10^{4}\right.$ cells/24-well plate) were infected with Ad-Mieap. On day 1 after infection, the cells were fixed in phosphate buffered $2.5 \%$ glutaraldehyde, and subsequently post-fixed in $1 \% \mathrm{OsO}_{4}$ at $4{ }^{\circ} \mathrm{C}$ for $2 \mathrm{~h}$. Then, the specimens were dehydrated in a graded ethanol and embedded in the epoxy resin. Ultrathin sections $(75 \mathrm{~nm})$ were obtained by ultramicrotome technique. Ultrathin sections stained with uranyl acetate and lead staining solution were observed on a transmission electron microscope $\mathrm{H}-7500$ (Hitachi) at $80 \mathrm{kV}$.

The LS174T (control and Mieap-KD) cells cultured under a normal condition were also processed for TEM as mentioned above with following modifications. $2 \%$ glutaraldehyde was used instead for prefixation. $2 \% \mathrm{OsO}_{4}$ was used instead for postfixation. 80-90 nm of ultrathin sections were obtained, and observed on a transmission electron microscope H-7600 (Hitachi) at $100 \mathrm{kV}$.

The kidney and liver specimens were collected from an 18-week-old WT and a 16-week-old Mieap ${ }^{-1-}$ male mice. The specimens cut into approximately $3 \times 3 \times 3 \mathrm{~mm}^{3}$ were also processed for TEM as the above mentioned A549-cont cells were processed. However, mixture of $2 \%$ paraformaldehyde and $2 \%$ glutaraldehyde was used instead for prefixation.

\section{Post-embedding immunoelectron microscopy}

The A549-cont cells $\left(2 \times 10^{5}\right.$ cells $/ 35 \mathrm{~mm}$ glass bottom dish) were infected with Ad-Mieap. On day 1 after infection, the cells were fixed by $4 \%$ paraformaldehyde and $0.025 \%$ glutaraldehyde in $0.1 \mathrm{M}$ $\mathrm{PB}(\mathrm{pH} 7.4)$ for $1 \mathrm{~h}$ at $4^{\circ} \mathrm{C}$. After fixation, the cells were washed with $0.1 \mathrm{M} \mathrm{PB} \mathrm{(pH} \mathrm{7.4)} \mathrm{for} 16 \mathrm{~h}$ at $4^{\circ} \mathrm{C}$, dehydrated in a graded series of ethanol, and infiltrated with LR White resin. Polymerization was performed in TAAB embedding capsules (TAAB) inverted on the glass bottom dishes for $3 \mathrm{~h}$ at $60^{\circ} \mathrm{C}$. Ultrathin sections $(75 \mathrm{~nm})$ were collected on nickel grids. After blocking with $3 \%$ BSA in PBS for $1 \mathrm{~h}$, the sections were incubated with anti-Mieap antibody (1:200) diluted in PBS with $0.05 \%$ Triton $\mathrm{X}-100$ for $2 \mathrm{~h}$ at RT. The sections were washed eight times with $0.15 \%$ glycine in PBS, and incubated with goat anti rabbit IgG $10 \mathrm{~nm}$ gold antibody (1:50) diluted in PBS with $0.05 \%$ Triton X-100 for $2 \mathrm{~h}$ at RT. The sections were washed eight times in PBS, and fixed by $1 \%$ glutaraldehyde in PBS for $5 \mathrm{~min}$. The sections were washed eight times in distilled water. The grids 
were embedded in a mixture containing $2.7 \%$ polyvinyl alcohol and $0.3 \%$ uranyl acetate. The sections on the grid were observed on a transmission electron microscope H-7500 (Hitachi) at 75 $\mathrm{kV}$.

\section{Sequence analyses of Mieap}

We analyzed phylogenetic spread of the Mieap orthologs using OrthoDB v10 (https://www.orthodb.org) (Kriventseva et al., 2019). Multiple sequence alignment for Mieap orthologs was constructed using Genetyx ver. 10. Prediction of the IDRs on amino acid sequence of Mieap was generated using VL3-BA (Uversky et al., 2007) of the PONDR server (http://www.pondr.com/) and collated with meta-prediction of the IDRs using DisMeta (http://www-nmr.cabm.rutgers.edu/bioinformatics/disorder/) (Huang et al., 2014). Prediction of the coiled-coil regions was using COILS (https://embnet.vital-it.ch/software/COILS_form.html) (Lupas et al., 1991). The hydrophobicity of Mieap was analyzed according to the Kyte-Doolittle scale (Kyte and Doolittle, 1982) using ProtScale (https://web.expasy.org/protscale/) (Wilkins et al., 1999). The linear net charge per residue of Mieap was analyzed using CIDER (http://pappulab.wustl.edu/CIDER/) (Holehouse et al., 2017).

\section{Analyses of confocal microscopy image data}

Throughout the study, the confocal microscopy images were taken with a FLUOVIEW FV3000 confocal laser scanning microscope (Olympus). For validation of the spatial relationship between MLDs and mApple-TOMM20, additional images were taken with a SpinSR10 spinning disk confocal super resolution microscope (Olympus). For Z-stack and time-lapse imaging, montage of differential interference contrast (DIC) and fluorescence images was built using MetaMorph ver. 7.8 (Molecular devices). 3D reconstruction was performed using a cellSens Imaging Software (Olympus). Line-scan profiles were acquired using MetaMorph ver. 7.8 (Molecular devices).

\section{FRAP experiments}

EGFP-Mieap, EGFP-Mieap $\Delta$ CC, EGFP-Mieap $\Delta 275$, and EGFP-Mieap $\Delta 496$ were expressed in the A549-cont cells to generate condensates by infection with Ad-EGFP-Mieap, Ad-EGFP-Mieap $\Delta C C$, Ad-EGFP-Mieap $\Delta 275$, and Ad-EGFP-Mieap $\Delta 496$, respectively. FRAP experiments were performed on a FLUOVIEW FV3000 confocal laser scanning microscope (Olympus), using a 60x/1.4 NA oil immersion objective (Olympus). The condensates were subjected to spot-bleach or full-bleach (bleaching the entire condensates). For spot-bleach, bleaching area was unified to $1.38 \mu \mathrm{m}$ in diameter. The condensates were imaged for $6 \mathrm{~s}$ acquiring 30 images prior to spot-bleach or $50 \mathrm{~s}$ acquiring 5 images prior to full-bleach. Photobleaching was done using a $488 \mathrm{~nm}$ laser at $10 \%$ laser power with $11.6 \mu \mathrm{s} / \mu \mathrm{m}$ exposure time or $1.4 \%$ laser power with $1.4 \mu \mathrm{s} / \mu \mathrm{m}$ exposure time as indicated. Time lapse images were acquired at $0.2 \mathrm{~ms}$ intervals for $60 \mathrm{~s}$ or $10 \mathrm{~s}$ intervals for 15 
min. The spot-bleach data of each construct were acquired from 15 different condensates. The full-bleach data of each construct were acquired from 10 different condensates.

\section{Expression and purification of GST and GST-Mieap}

Escherichia coli (BL21) transformed with the expression vectors were grown in $200 \mathrm{ml}$ of Luria-Bertani medium until OD600 was between 0.55-0.6 at $37^{\circ} \mathrm{C}$. Protein expression was induced with $100 \mu \mathrm{M}$ IPTG, and the bacteria were subsequently incubated for $3 \mathrm{~h}$ at $25^{\circ} \mathrm{C}$. After harvesting the bacteria by centrifugation at $3000 \times g$ for $10 \mathrm{~min}$ at $4{ }^{\circ} \mathrm{C}$, the pellets were lysed with lysis buffer (1\% Triton X-100 buffered in PBS supplemented with $1 \mathrm{mM}$ Phenylmethylsulfonyl fluoride), and sonicated $(20 \times 30 \mathrm{~s}$ bursts with $10 \mathrm{~s}$ rest between each burst $)$. The insoluble material was removed by centrifugation at $10,000 \mathrm{rpm}$ for $30 \mathrm{~min}$ at $4{ }^{\circ} \mathrm{C}$. The supernatant was incubated with glutathione-Sepharose 4B (Cytiva) pre-equilibrated with the lysis buffer at $4{ }^{\circ} \mathrm{C}$ overnight. After the beads were washed twice with lysis buffer, the proteins were eluted with elution buffer $(50 \mathrm{mM}$ Glutathione diluted in 50mM Tris- $\mathrm{HCl}, \mathrm{pH} 8.0$ ), and dialyzed at $4{ }^{\circ} \mathrm{C}$ overnight against PBS.

\section{Lipid-binding analysis}

For lipid-binding analysis, protein-lipid interactions on the lipid-spotted membranes were evaluated on the basis of fat blot assay (Munnik and Wierzchowiecka, 2013). Natural CL, PC, and PE derived from bovine heart (Olbracht serdary research laboratories) were diluted with chloroform/methanol/1N HCl (80:80:1). $1 \mu$ of each diluted lipid was spotted onto a PVDF membrane (Cytiva) for antigen-antibody reaction using the anti-Mieap antibody or a nitrocellulose membrane (Cytiva) for antigen-antibody reaction using an anti-GST antibody to align spots with increasing amounts of the lipids ranging from 0-667 pmol. Here, the approximate molarities of CL, PC, and PE calculated from the molecular weights of tetralinoleoyl CL, distearoyl PC, and distearoyl PC were used, respectively. After membranes were blocked with blocking buffer (3\% fatty-acid free BSA diluted in $50 \mathrm{mM}$ Tris- $\mathrm{HCl}, 150 \mathrm{mM} \mathrm{NaCl}, \mathrm{pH} 7.5$ ) for 1 hour, the membranes were incubated with $2.5 \mu \mathrm{g} / \mathrm{ml}$ of GST-Mieap or GST protein diluted in the blocking buffer containing $0.1 \%$ Tween 20 overnight. The membranes were incubated with the primary antibody (rabbit anti-Mieap antibody or rabbit anti-GST antibody) diluted in the blocking buffer containing $0.06 \%$ Tween 20 (1:1000) for $3.5 \mathrm{~h}$, and subsequently, a secondary antibody (goat anti-rabbit antibody conjugated to horseradish-peroxidase) diluted in the blocking buffer containing $0.06 \%$ Tween 20 (1:10000) for 1 hour. ECL Western Blotting Detection Reagents (Cytiva) was used to detect HRP and the chemiluminescence was visualized with the ImageQuant LAS 4000 system (Cytiva).

\section{Lipid preparation}

Lipid preparation was performed as described previously elsewhere (Shindou et al., 2017; Yamamoto et al., 2018). Briefly, total lipids were extracted from the samples with the Bligh-Dyer method (Bligh and Dyer, 1959). An aliquot of the lower/organic phase was added with an equal 
volume of methanol before being loaded onto a DEAE-cellulose column (Wako chemical) pre-equilibrated with chloroform. After successive washes with chloroform/methanol (1:1, v/v), the acidic phospholipids were eluted with chloroform/methanol/HCl/water $(12: 12: 1: 1, \mathrm{v} / \mathrm{v})$, followed by evaporation to dryness to give a residue, which was resolved in methanol.

\section{Mass spectrometric analyses of $\mathbf{C L}$}

Analyses were performed on a LC/MS/MS system consisting of a Q-Exactive Plus mass spectrometer (Thermo Fisher Scientific) equipped with an electrospray ionization source, and an UltiMate 3000 system (Thermo Fisher Scientific). The lipid samples were separated on Waters X-Bridge $\mathrm{C} 18$ column $(3.5 \mu \mathrm{m}, 150 \mathrm{~mm} \times 1.0 \mathrm{~mm}$ i.d. $)$ at $40^{\circ} \mathrm{C}$ using a gradient solvent system as follows: mobile phase A (isopropanol/methanol/water $(5: 1: 4, \mathrm{v} / \mathrm{v} / \mathrm{v})$ supplemented with $5 \mathrm{mM}$ ammonium formate and $0.05 \%$ ammonium hydroxide (28\% in water))/mobile phase B (isopropanol supplemented with $5 \mathrm{mM}$ ammonium formate and $0.05 \%$ ammonium hydroxide (28\% in water)) ratios of $60 \% / 40 \%$ ( $0 \mathrm{~min}$ ), 40\%/60\% (1 $\mathrm{min}), 20 \% / 80 \%$ ( $9 \mathrm{~min}$ ), 5\%/95\% (11-30 $\mathrm{min}$ ), 95\%/5\% (31-35 min) and 60\%/40\% (45 min). Flow rate was $25 \mu \mathrm{L} / \mathrm{min}$. The source and ion transfer parameters applied were as followed: spray voltage $3.0 \mathrm{kV}$. For negative ionization modes, the sheath gas and the capillary temperature were maintained at 60 and $320{ }^{\circ} \mathrm{C}$, respectively. The Orbitrap mass analyzer was operated at a resolving power of 70,000 in full-scan mode (scan range: 200-1800 m/z; automatic gain control (AGC) target:3e6) and of 35,000 in the Top 20 data-dependent MS2 mode (stepped normalized collision energy: 20, 30 and 40; isolation window: $4.0 \mathrm{~m} / \mathrm{z}$; AGC target: 1e5). Identification of CL molecular species was performed using with LipidSearch4.2 software (Mitsui knowledge industry)

\section{Real-time ATP rate assay}

LS174T-cont and Mieap-KD cells were seeded at a density of $2.5 \times 10^{4}$ cells/well in nonaplicate on a Seahorse XF24 Cell Culture Microplate. The cells were incubated at $37^{\circ} \mathrm{C}$ in a humidified chamber with $5 \% \mathrm{CO}_{2}$. $18 \mathrm{~h}$ after seeding, culture medium was replaced with XF DMEM medium $\mathrm{pH} 7.4$ supplemented with $25 \mathrm{mM}$ glucose and $2 \mathrm{mM}$ L-glutamine through three washes. After the cells were incubated at $37{ }^{\circ} \mathrm{C}$ in a non- $\mathrm{CO}_{2}$ incubator for minutes, the cell culture plate was loaded to a Seahorse XFe24 Analyzer. Oxygen consumption rate (OCR) and extracellular acidification rate (ECAR) were recorded before and after serial injections of oligomycin and rotenone/antimycin A to make a final concentration of $0.5 \mu \mathrm{M}$ and $0.5 \mu \mathrm{M}$, respectively.

\section{Flow cytometric analysis}

The LS174T-cont and Mieap-KD cells cultured under a normal condition were harvested by trypsin-EDTA treatment. After adding complete growth media to inactivate trypsin, cells were centrifugated, washed with PBS, and incubated with $5 \mu \mathrm{M} 2^{\prime}, 7^{\prime}$-dichlorofluorescin-diacetate (Sigma) for $20 \mathrm{~min}$ at $37^{\circ} \mathrm{C}$. After washed with PBS, the cells were immediately analyzed with an EC800 flow cytometry analyzer (Sony) using the $488 \mathrm{~nm}$ line. 


\section{Quantification and statistical analysis}

\section{FRAP data}

The fluorescence recovery rates in Figure 3B-3D were calculated using a cellSens Imaging Software (Olympus), in which the intensity initially acquired after bleach was equated to 0 and the pre-bleach intensity was equated to 1 , and the normalized average fluorescence recovery was plotted in JMP 14.2.0 (SAS).

\section{Real-time ATP rate assay data}

The graph for the ATP production rates in Figure 7B were generated with Agilent Seahorse XF Real-Time ATP Rate Assay Report Generator.

\section{Cristae data}

For quantification of the cristae data in Figure 7C, 7E, and 7G, the cristae area and the outline of mitochondrial section in TEM images were marked manually using Adobe Photoshop CC, where normal cristae morphology was identified by the presence of lamellar structures with distinct osmium staining. Any aberrant cristae-like structures which were not observed in the mitochondria of WT were excluded. Subsequently, the ratio of the cristae area per mitochondrial section was calculated from the indicated number of mitochondria in legends of Figure 7D, 7F and 7H, using Image J (Schneider et al., 2012), and the violin plots were generated in JMP 14.2.0 (SAS). Statistical analysis was conducted using Student's two-tailed t-test. 


\section{Supplemental information}

-Supplemental tables

$\circ$ Table S1. Mass spectrometric data of CL under the exogenous and physiological expression of Mieap, related to Figure 5

$\circ$ Table S2. Oligonucleotides used in this paper

-Supplemental figures

$\circ$ Figure S1. Analyses of the Mieap orthologs, amino acid residues enriched in Mieap sequence, ant the evolutionary conservation, related to Figure 2

- Figure S2. Z-stack images showing the spatial relationship between the MLDs and the mitochondrial outer membranes, related to Figure 4

- Figure S3. Verification of subcellular localization of the fluorescence-tagged proteins, related to Figure 4

- Figure S4. Screening of the mitochondrial molecules involved in phase separation by MLDs, related to Figure 4

$\circ$ Figure S5. Verification of subcellular localization of the fluorescence-tagged proteins, related to Figure 6

- Figure S6. Impacts of Mieap deficiency, related to Figure 7

-Supplemental Movies

- Video S1. Time-lapse imaging of the A549-cont cells expressing EGFP-Mieap, co-stained with MitoTracker Red, related to Figure 1.

- Video S2. Time-lapse imaging of the self-fusing condensates comprised of EGFP-Mieap in the A549-cont cell, related to Figure 1.

$\circ$ Video S3. Z-stack imaging of the condensates comprised of EGFP-Mieap, EGFP-Mieap $\Delta C C$, EGFP-Mieap $\Delta 275$, or EGFP-Mieap $\Delta 496$ in the A549-cont cells, co-stained without/with MitoTracker Red, related to Figure 2.

- Video S4. Z-stack, 3D, and time-lapse imaging, showing the spatial relationship between the MLDs and mApple-TOMM20 in the A549-cont cells, related to Figure 4.

- Video S5. Z-stack and time-lapse imaging for screening molecules involved in phase separation by MLDs, where EGFP-BNIP3, EGFP-NIX, AcGFP1-Mito, DsRed2-Mito, and SYBR Green I were examined, related to Figure 4.

- Video S6. Z-stack and/or time-lapse imaging which show involvement of cardiolipin (CL) visualized with 10-nonylacridine orange bromide (NAO) and CL-binding proteins visualized with EGFP-tagged cytochrome $c$, ATP5F1B, and PHB2 in phase separation by MLDs in the A549-cont cells, related to Figure 4.

- Video S7. Z-stack imaging of molecules, including EGFP-tagged TAMM41, PGS1, PTPMT1, CRLS1, PLA2G6, TAZ, PRELI, LONP1, and PLD6, which shows the specific involvement of molecules associated with CL metabolism in phase separation by MLDs in the A549-cont cells, related to Figure 6. 


\section{References}

Alberti, S., Gladfelter, A., and Mittag, T. (2019). Considerations and Challenges in Studying Liquid-Liquid Phase Separation and Biomolecular Condensates. Cell 176, 419-434.

Almagro Armenteros, J.J., Salvatore, M., Emanuelsson, O., Winther, O., von Heijne, G., Elofsson, A., and Nielsen, H. (2019). Detecting sequence signals in targeting peptides using deep learning. Life Sci. Alliance 2. e201900429

An, S.G., Kumar, R., Sheets, E.D., and Benkovic, S.J. (2008). Reversible compartmentalization of de novo purine biosynthetic complexes in living cells. Science 320, 103-106.

Ardail, D., Privat, J.P., Egret-Charlier, M., Levrat, C., Lerme, F., and Louisot, P. (1990). Mitochondrial contact sites. Lipid composition and dynamics. J. Biol. Chem. 265, 18797-18802.

Bannai, H., Tamada, Y., Maruyama, O., Nakai, K., and Miyano, S. (2002). Extensive feature detection of N-terminal protein sorting signals. Bioinformatics (Oxford, England) 18, 298-305.

Belazi, D., Sole-Domenech, S., Johansson, B., Schalling, M., and Sjovall, P. (2009). Chemical analysis of osmium tetroxide staining in adipose tissue using imaging ToF-SIMS. Histochem. Cell Biol. 132, 105-115.

Bligh, E.G., and Dyer, W.J. (1959). A rapid method of total lipid extraction and purification. Can. J. Biochem. Physiol. 37, 911-917.

Boeynaems, S., Alberti, S., Fawzi, N.L., Mittag, T., Polymenidou, M., Rousseau, F., Schymkowitz, J., Shorter, J., Wolozin, B., Van Den Bosch, L., et al. (2018). Protein Phase Separation: A New Phase in Cell Biology. Trends Cell Biol. 28, 420-435.

Bota, D.A., and Davies, K.J. (2002). Lon protease preferentially degrades oxidized mitochondrial aconitase by an ATP-stimulated mechanism. Nat. Cell Biol. 4, 674-680.

Bracha, D., Walls, M.T., and Brangwynne, C.P. (2019). Probing and engineering liquid-phase organelles. Nat. Biotechnol. 37, 1435-1445.

Case, L.B., Zhang, X., Ditlev, J.A., and Rosen, M.K. (2019). Stoichiometry controls activity of phase-separated clusters of actin signaling proteins. Science 363, 1093-1097.

Castellana, M., Wilson, M.Z., Xu, Y.F., Joshi, P., Cristea, I.M., Rabinowitz, J.D., Gitai, Z., and Wingreen, N.S. (2014). Enzyme clustering accelerates processing of intermediates through metabolic channeling. Nat. Biotechnol. 32, 1011-1018.

Chao, H., Anthonymuthu, T.S., Kenny, E.M., Amoscato, A.A., Cole, L.K., Hatch, G.M., Ji, J., Kagan, V.E., and Bayır, H. (2018). Disentangling oxidation/hydrolysis reactions of brain mitochondrial cardiolipins in pathogenesis of traumatic injury. JCI insight 3. e97677

Choi, S.Y., Huang, P., Jenkins, G.M., Chan, D.C., Schiller, J., and Frohman, M.A. (2006). A common lipid links Mfn-mediated mitochondrial fusion and SNARE-regulated exocytosis. Nat. Cell Biol. 8, 1255-1262. 
Cullis, P.t., and Kruijff, B.d. (1979). Lipid polymorphism and the functional roles of lipids in biological membranes. Biochim. Biophys. Acta (BBA)-Reviews on Biomembranes 559, 399-420.

Cuylen, S., Blaukopf, C., Politi, A.Z., Muller-Reichert, T., Neumann, B., Poser, I., Ellenberg, J., Hyman, A.A., and Gerlich, D.W. (2016). Ki-67 acts as a biological surfactant to disperse mitotic chromosomes. Nature 535, 308-312.

Dan, X., Babbar, M., Moore, A., Wechter, N., Tian, J., Mohanty, J.G., Croteau, D.L., and Bohr, V.A. (2020). DNA damage invokes mitophagy through a pathway involving Spata18. Nucleic Acids Res. 48, 6611-6623.

De Gennes, P. G. (1985). Wetting: statics and dynamics. Rev. Mod. Phys. 57, 827-863.

Du, M.J., and Chen, Z.J.J. (2018). DNA-induced liquid phase condensation of cGAS activates innate immune signaling. Science 361, 704-709.

Dudek, J. (2017). Role of cardiolipin in mitochondrial signaling pathways. Front. Cell Dev. Biol. 5, 90.

Dutschk, V., Calvimontes, A., and Stamm, M. (2012). Wetting dynamics of aqueous surfactant solutions on polymer surfaces. In Drops and Bubbles in Contact with Solid Surfaces, M. Ferrari, L. Liggieri, R. Miller, ed. (Boca Raton, USA: CRC press Taylor \& Francis Group), pp. 71-90.

Gaowa, S., Futamura, M., Tsuneki, M., Kamino, H., Tajima, J.Y., Mori, R., Arakawa, H., and Yoshida, K. (2018). Possible role of p53/Mieap-regulated mitochondrial quality control as a tumor suppressor in human breast cancer. Cancer Sci. 109, 3910-3920.

Ghosh, S., Iadarola, D.M., Ball, W.B., and Gohil, V.M. (2019). Mitochondrial dysfunctions in Barth syndrome. IUBMB life $71,791-801$.

Gonzalvez, F., and Gottlieb, E. (2007). Cardiolipin: setting the beat of apoptosis. Apoptosis 12, 877-885.

Goldstein, J.C., Waterhouse, N.J., Juin, P., Evan, G.I., and Green, D.R. (2000). The coordinate release of cytochrome c during apoptosis is rapid, complete and kinetically invariant. Nat. Cell Biol. 2, 156-162.

Hinzpeter, F., Gerland, U., and Tostevin, F. (2017). Optimal Compartmentalization Strategies for Metabolic Microcompartments. Biophys. J. 112, 767-779.

Hnisz, D., Shrinivas, K., Young, R.A., Chakraborty, A.K., and Sharp, P.A. (2017). A phase separation model for transcriptional control. Cell 169, 13-23.

Holehouse, A.S., Das, R.K., Ahad, J.N., Richardson, M.O., and Pappu, R.V. (2017). CIDER: Resources to Analyze Sequence-Ensemble Relationships of Intrinsically Disordered Proteins. Biophys. J. 112, 16-21.

Huang, W.Y.C., Alvarez, S., Kondo, Y., Lee, Y.K., Chung, J.K., Lam, H.Y.M., Biswas, K.H., Kuriyan, J., and Groves, J.T. (2019). A molecular assembly phase transition and kinetic proofreading modulate Ras activation by SOS. Science 363, 1098-1103. 
Huang, Y.J., Acton, T.B., and Montelione, G.T. (2014). DisMeta: a meta server for construct design and optimization. Methods Mol. Biol. 1091, 3-16.

Ikon, N., and Ryan, R.O. (2017). Cardiolipin and mitochondrial cristae organization. Biochim. Biophys. Acta (BBA)-Biomembranes 1859, 1156-1163.

Jin, M.Y., Fuller, G.G., Han, T., Yao, Y., Alessi, A.F., Freeberg, M.A., Roach, N.P., Moresco, J.J., Karnovsky, A., Baba, M., et al. (2017). Glycolytic Enzymes Coalesce in G Bodies under Hypoxic Stress. Cell Rep. 20, 895-908.

Kaewsuya, P., Danielson, N.D., and Ekhterae, D. (2007). Fluorescent determination of cardiolipin using 10-N-nonyl acridine orange. Anal. Bioanal. Chem. 387, 2775-2782.

Kamino, H., Nakamura, Y., Tsuneki, M., Sano, H., Miyamoto, Y., Kitamura, N., Futamura, M., Kanai, Y., Taniguchi, H., Shida, D., et al. (2016). Mieap-regulated mitochondrial quality control is frequently inactivated in human colorectal cancer. Oncogenesis 5, e181.

Kasahara, T., Kubota-Sakashita, M., Nagatsuka, Y., Hirabayashi, Y., Hanasaka, T., Tohyama, K., and Kato, T. (2019). Cardiolipin is essential for early embryonic viability and mitochondrial integrity of neurons in mammals. The FASEB Journal 34, 1465-1480.

Kitamura, N., Nakamura, Y., Miyamoto, Y., Miyamoto, T., Kabu, K., Yoshida, M., Futamura, M., Ichinose, S., and Arakawa, H. (2011). Mieap, a p53-Inducible Protein, Controls Mitochondrial Quality by Repairing or Eliminating Unhealthy Mitochondria. PLoS One 6, e16060.

Kohnhorst, C.L., Kyoung, M., Jeon, M., Schmitt, D.L., Kennedy, E.L., Ramirez, J., Bracey, S.M., Luu, B.T., Russell, S.J., and An, S. (2017). Identification of a multienzyme complex for glucose metabolism in living cells. J. Biol. Chem. 292, 9191-9203.

Kojima, T., and Takayama, S. (2018). Membraneless Compartmentalization Facilitates Enzymatic Cascade Reactions and Reduces Substrate Inhibition. ACS Appl. Mater. Interfaces 10, 32782-32791.

Kriventseva, E.V., Kuznetsov, D., Tegenfeldt, F., Manni, M., Dias, R., Simao, F.A., and Zdobnov, E.M. (2019). OrthoDB v10: sampling the diversity of animal, plant, fungal, protist, bacterial and viral genomes for evolutionary and functional annotations of orthologs. Nucleic Acids Res. 47, D807-D811.

Kyte, J., and Doolittle, R.F. (1982). A simple method for displaying the hydropathic character of a protein. J. Mol. Biol. 157, 105-132.

Lee, H., DeLoache, W.C., and Dueber, J.E. (2012). Spatial organization of enzymes for metabolic engineering. Metab. Eng. 14, 242-251.

Lee, J.H., Park, A., Oh, K.-J., Lee, S.C., Kim, W.K., and Bae, K.-H. (2019). The role of adipose tissue mitochondria: Regulation of mitochondrial function for the treatment of metabolic diseases. Int. J. Mol. Sci. $20,4924$.

Lee, K., Ivanova, N., Starov, V., Hilal, N., and Dutschk, V. (2008). Kinetics of wetting and spreading by 
aqueous surfactant solutions. Adv. Colloid Interface Sci. 144, 54-65.

Lee, K.H., Zhang, P.P., Kim, H.J., Mitrea, D.M., Sarkar, M., Freibaum, B.D., Cika, J., Coughlin, M., Messing, J., Molliex, A., et al. (2016). C9orf72 Dipeptide Repeats Impair the Assembly, Dynamics, and Function of Membrane-Less Organelles. Cell 167, 774-788.

Li, J., Romestaing, C., Han, X., Li, Y., Hao, X., Wu, Y., Sun, C., Liu, X., Jefferson, L.S., Xiong, J., et al. (2010). Cardiolipin remodeling by ALCAT1 links oxidative stress and mitochondrial dysfunction to obesity. Cell Metab. 12, 154-165.

Li, Y., Lipowsky, R., and Dimova, R. (2008). Transition from complete to partial wetting within membrane compartments. J. Am. Chem. Soc. 130, 12252-12253.

Lupas, A., Van Dyke, M., and Stock, J. (1991). Predicting coiled coils from protein sequences. Science 252, $1162-1164$.

Macfarlane, M.G. (1958). Structure of cardiolipin. Nature 182, 946.

Malhotra, A., Edelman-Novemsky, I., Xu, Y., Plesken, H., Ma, J.P., Schlame, M., and Ren, M.D. (2009). Role of calcium-independent phospholipase $\mathrm{A}(2)$ in the pathogenesis of Barth syndrome. Proc. Natl. Acad. Sci. U. S. A. 106, 2337-2341.

Martin, E.W., and Mittag, T. (2019). Dwelling at membranes promotes decisive signaling. Science 363, $1036-1037$.

McClements, D.J. (2007). Critical review of techniques and methodologies for characterization of emulsion stability. Crit. Rev. Food Sci. Nutr. 47, 611-649.

Miyamoto, T., Kitamura, N., Ono, M., Nakamura, Y., Yoshida, M., Kamino, H., Murai, R., Yamada, T., and Arakawa, H. (2012). Identification of $14-3-3 \gamma$ as a Mieap-interacting protein and its role in mitochondrial quality control. Sci. Rep. 2, 379.

Miyamoto, Y., Kitamura, N., Nakamura, Y., Futamura, M., Miyamoto, T., Yoshida, M., Ono, M., Ichinose, S., and Arakawa, H. (2011). Possible Existence of Lysosome-Like Organella within Mitochondria and Its Role in Mitochondrial Quality Control. PLoS One 6. e16054.

Molliex, A., Temirov, J., Lee, J., Coughlin, M., Kanagaraj, A.P., Kim, H.J., Mittag, T., and Taylor, J.P. (2015). Phase Separation by Low Complexity Domains Promotes Stress Granule Assembly and Drives Pathological Fibrillization. Cell 163, 123-133.

Munnik, T., and Wierzchowiecka, M. (2013). Lipid-binding analysis using a fat blot assay. Methods Mol. Biol. 1009, 253-259.

Mussazhanova, Z., Shimamura, M., Kurashige, T., Ito, M., Nakashima, M., and Nagayama, Y. (2020). Causative role for defective expression of mitochondria-eating protein in accumulation of mitochondria in thyroid oncocytic cell tumors. Cancer Sci. 111, 2814-2823. 
Nakamura, Y., Kitamura, N., Shinogi, D., Yoshida, M., Goda, O., Murai, R., Kamino, H., and Arakawa, H. (2012). BNIP3 and NIX Mediate Mieap-Induced Accumulation of Lysosomal Proteins within Mitochondria. PLoS One 7, e30767.

Okuyama, K., Kitajima, Y., Egawa, N., Kitagawa, H., Ito, K., Aishima, S., Yanagihara, K., Tanaka, T., and Noshiro, H. (2019). Mieap-induced accumulation of lysosomes within mitochondria (MALM) regulates gastric cancer cell invasion under hypoxia by suppressing reactive oxygen species accumulation. Sci. Rep. 9 , 2822.

Oda, K., Arakawa, H., Tanaka, T., Matsuda, K., Tanikawa, C., Mori, T., Nishimori, H., Tamai, K., Tokino, T., Nakamura, Y., et al. (2000). p53AIP1, a potential mediator of p53-dependent apoptosis, and its regulation by Ser-46-phosphorylated p53. Cell 102, 849-862.

Oshima, H., Matsunaga, A., Fujimura, T., Tsukamoto, T., Taketo, M.M., and Oshima, M. (2006). Carcinogenesis in mouse stomach by simultaneous activation of the Wnt signaling and prostaglandin E-2 pathway. Gastroenterology 131, 1086-1095.

Paradies, G., Paradies, V., De Benedictis, V., Ruggiero, F.M., and Petrosillo, G. (2014). Functional role of cardiolipin in mitochondrial bioenergetics. Biochim. Biophys. Acta (BBA)-Bioenergetics 1837, 408-417.

Paradies, G., Paradies, V., Ruggiero, F.M., and Petrosillo, G. (2019). Role of cardiolipin in mitochondrial function and dynamics in health and disease: Molecular and pharmacological aspects. Cells 8, 728.

Pennington, E.R., Funai, K., Brown, D.A., and Shaikh, S.R. (2019). The role of cardiolipin concentration and acyl chain composition on mitochondrial inner membrane molecular organization and function. Biochim. Biophys. Acta-Mol. Cell Biol. Lipids 1864, 1039-1052.

Planas-Iglesias, J., Dwarakanath, H., Mohammadyani, D., Yanamala, N., Kagan, V.E., and Klein-Seetharaman, J. (2015). Cardiolipin Interactions with Proteins. Biophys. J. 109, 1282-1294.

Potting, C., Tatsuta, T., König, T., Haag, M., Wai, T., Aaltonen, M.J., and Langer, T. (2013). TRIAP1/PRELI complexes prevent apoptosis by mediating intramitochondrial transport of phosphatidic acid. Cell Metab. 18, $287-295$.

Prouteau, M., and Loewith, R. (2018). Regulation of Cellular Metabolism through Phase Separation of Enzymes. Biomolecules 8, 160.

Rai, A.K., Chen, J.X., Selbach, M., and Pelkmans, L. (2018). Kinase-controlled phase transition of membraneless organelles in mitosis. Nature 559, 211-216.

Reed, M.C., Lieb, A., and Nijhout, H.F. (2010). The biological significance of substrate inhibition: a mechanism with diverse functions. Bioessays 32, 422-429.

Ren, M.D., Phoon, C.K.L., and Schlame, M. (2014). Metabolism and function of mitochondrial cardiolipin. Prog. Lipid Res. 55, 1-16.

Rosen, M.J., and Kunjappu, J.T. (2012). Surfactants and interfacial phenomena (Hoboken, USA: John Wiley 
\& Sons).

Sabari, B.R., Dall'Agnese, A., Boija, A., Klein, I.A., Coffey, E.L., Shrinivas, K., Abraham, B.J., Hannett, N.M., Zamudio, A.V., Manteiga, J.C., et al. (2018). Coactivator condensation at super-enhancers links phase separation and gene control. Science 361 , eaar3958.

Schlame, M., and Greenberg, M.L. (2017). Biosynthesis, remodeling and turnover of mitochondrial cardiolipin. Biochim. Biophys. Acta-Mol. Cell Biol. Lipids 1862, 3-7.

Schmitt, D.L., and An, S. (2017). Spatial Organization of Metabolic Enzyme Complexes in Cells. Biochemistry 56, 3184-3196.

Schneider, C.A., Rasband, W.S., and Eliceiri, K.W. (2012). NIH Image to ImageJ: 25 years of image analysis. Nat. Methods 9, 671-675.

Schöttl, T., Kappler, L., Fromme, T., and Klingenspor, M. (2015). Limited OXPHOS capacity in white adipocytes is a hallmark of obesity in laboratory mice irrespective of the glucose tolerance status. Mol. Metab. 4, 631-642.

Serricchio, M., Vissa, A., Kim, P.K., Yip, C.M., and McQuibban, G.A. (2018). Cardiolipin synthesizing enzymes form a complex that interacts with cardiolipin-dependent membrane organizing proteins. Biochim. Biophys. Acta-Mol. Cell Biol. Lipids 1863, 447-457.

Shin, Y., and Brangwynne, C.P. (2017). Liquid phase condensation in cell physiology and disease. Science 357, eaaf4382.

Shindou, H., Koso, H., Sasaki, J., Nakanishi, H., Sagara, H., Nakagawa, K.M., Takahashi, Y., Hishikawa, D., Iizuka-Hishikawa, Y., Tokumasu, F., et al. (2017). Docosahexaenoic acid preserves visual function by maintaining correct disc morphology in retinal photoreceptor cells. J. Biol. Chem. 292, 12054-12064.

Soro-Arnaiz, I., Li, Q.O.Y., Torres-Capelli, M., Meléndez-Rodríguez, F., Veiga, S., Veys, K., Sebastian, D., Elorza, A., Tello, D., Hernansanz-Agustín, P., et al. (2016). Role of mitochondrial complex IV in age-dependent obesity. Cell Rep. 16, 2991-3002.

Srere, P.A. (1987). COMPLEXES OF SEQUENTIAL METABOLIC ENZYMES. Annu. Rev. Biochem. 56, 89-124.

Strulson, C.A., Molden, R.C., Keating, C.D., and Bevilacqua, P.C. (2012). RNA catalysis through compartmentalization. Nat. Chem. 4, 941-946.

Tsuneki, M., Nakamura, Y., Kinjo, T., Nakanishi, R., and Arakawa, H. (2015). Mieap suppresses murine intestinal tumor via its mitochondrial quality control. Sci. Rep. 5, 12472.

Uversky, V.N., Radivojac, P., Iakoucheva, L.M., Obradovic, Z., and Dunker, A.K. (2007). Prediction of intrinsic disorder and its use in functional proteomics. Methods Mol. Biol. 408, 69-92.

Welch, G.R. (1977). On the role of organized multienzyme systems in cellular metabolism: a general 
synthesis. In Prog. Biophys. Mol. Biol. (London, UK: Elsevier), pp. 103-191.

Wilkins, M.R., Gasteiger, E., Bairoch, A., Sanchez, J.C., Williams, K.L., Appel, R.D., and Hochstrasser, D.F. (1999). Protein identification and analysis tools in the ExPASy server. Methods Mol. Biol. 112, 531-552.

Woodruff, J.B., Gomes, B.F., Widlund, P.O., Mahamid, J., Honigmann, A., and Hyman, A.A. (2017). The centrosome is a selective condensate that nucleates microtubules by concentrating tubulin. Cell 169, 1066-1077.

Yamamoto, T., Endo, J., Kataoka, M., Matsuhashi, T., Katsumata, Y., Shirakawa, K., Yoshida, N., Isobe, S., Moriyama, H., Goto, S., et al. (2018). Decrease in membrane phospholipids unsaturation correlates with myocardial diastolic dysfunction. PLoS One 13, e0208396.

Ye, C., Shen, Z., and Greenberg, M.L. (2016). Cardiolipin remodeling: a regulatory hub for modulating cardiolipin metabolism and function. J. Bioenerg. Biomembr. 48, 113-123.

Zhao, E.M., Suek, N., Wilson, M.Z., Dine, E., Pannucci, N.L., Gitai, Z., Avalos, J.L., and Toettcher, J.E. (2019). Light-based control of metabolic flux through assembly of synthetic organelles. Nat. Chem. Biol. 15, 589-597. 
Figure 1

A
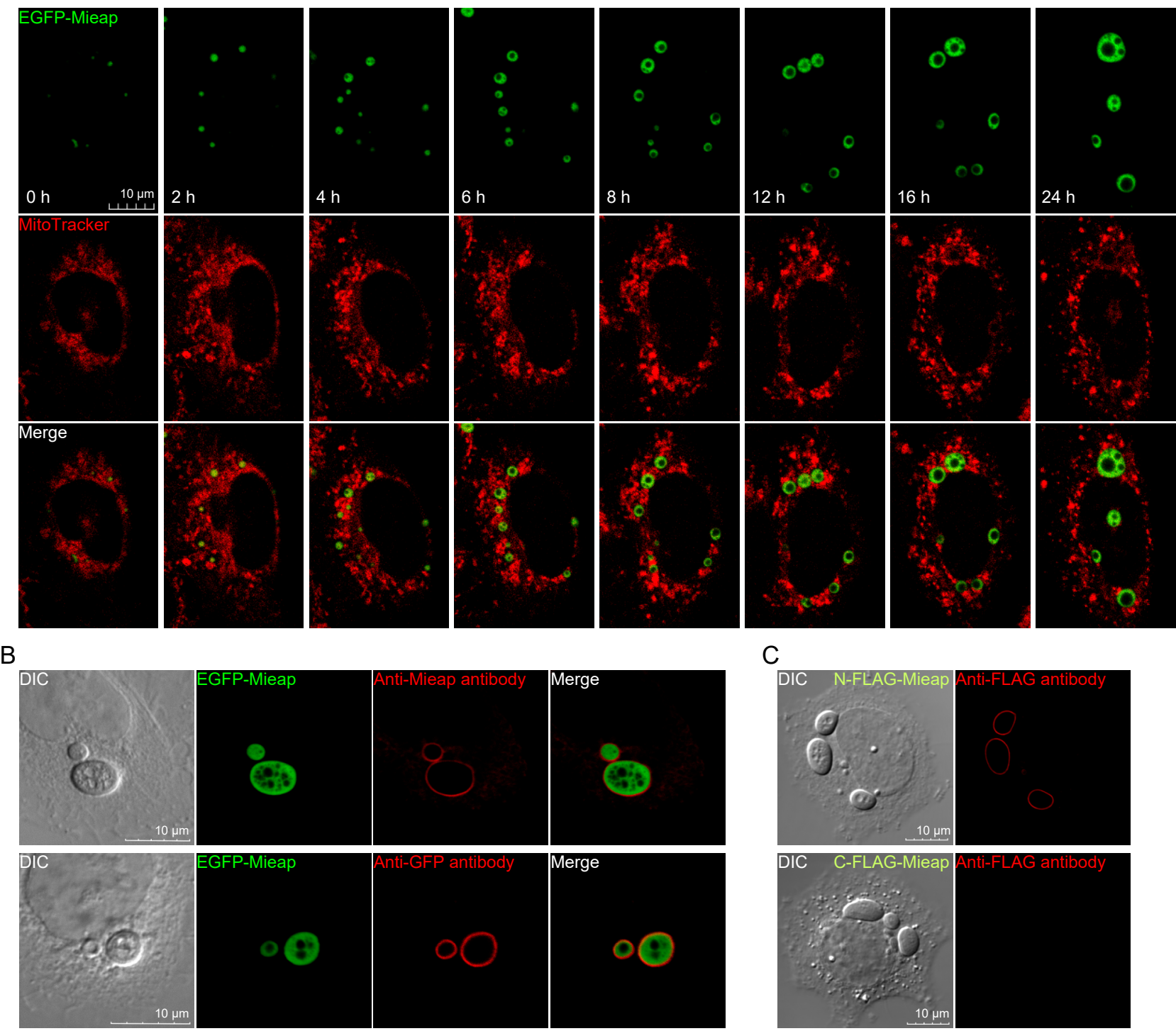

D

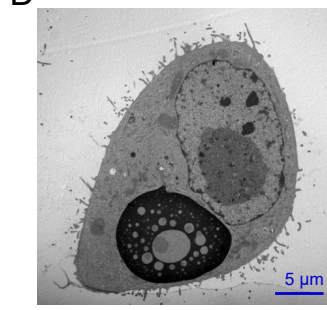

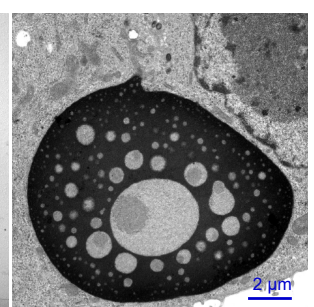

E

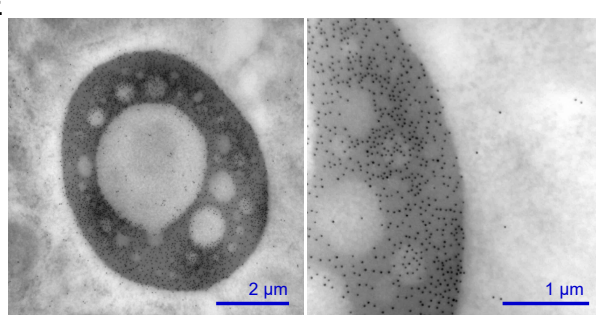

$F$

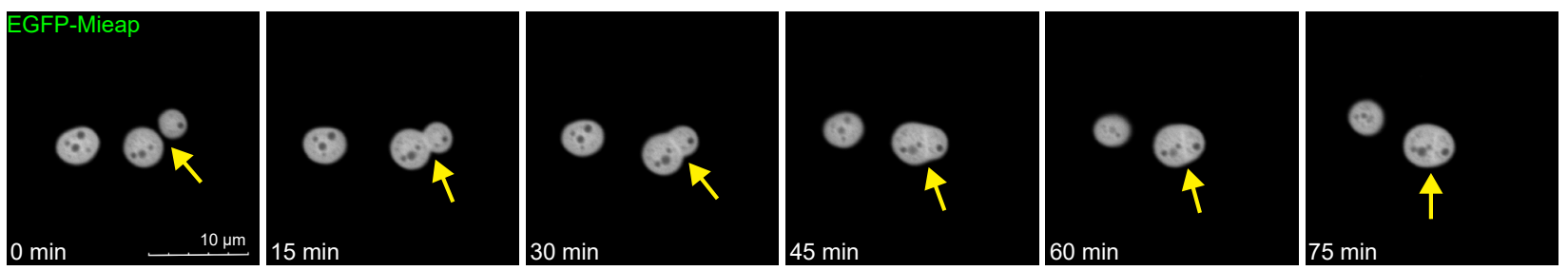


A
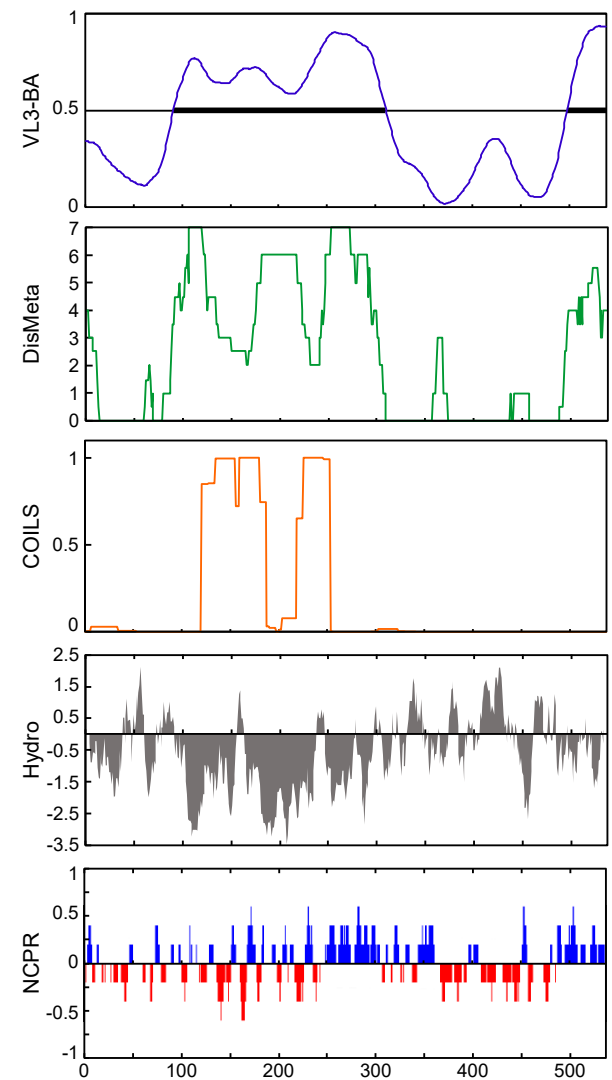

B

hydrophilic $\stackrel{1}{\longleftrightarrow}$ hydrophobic

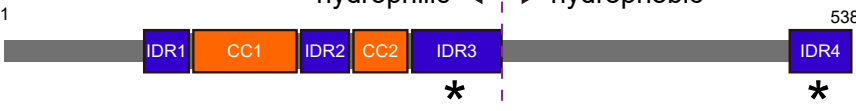

C

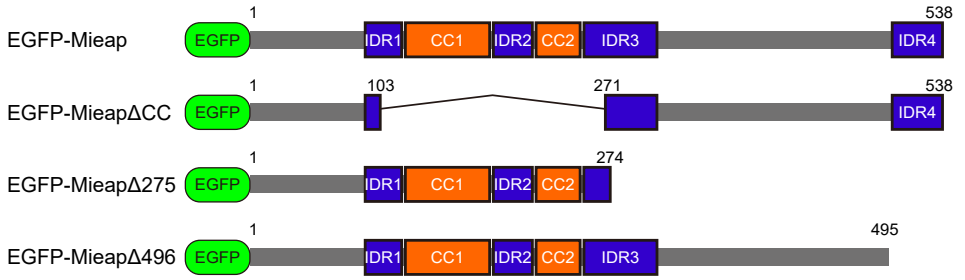

D
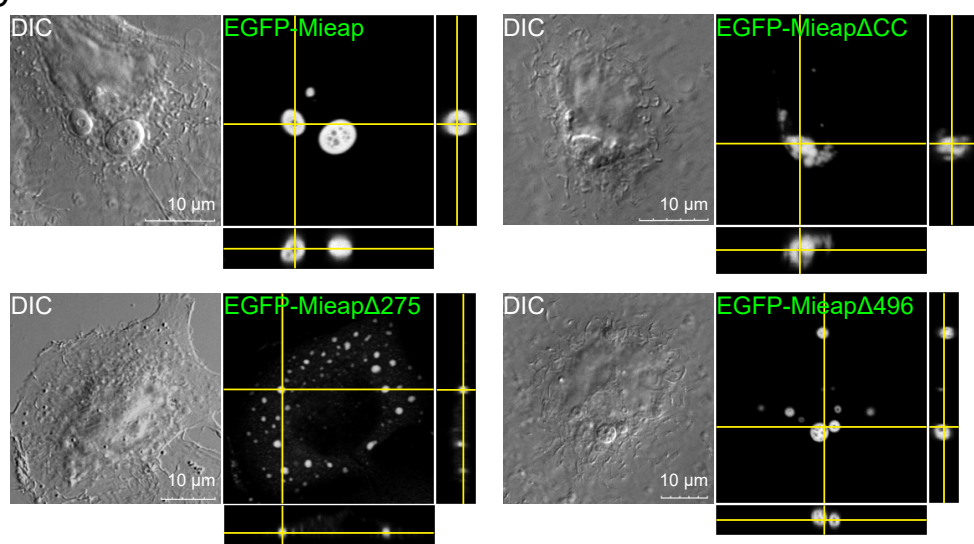

E

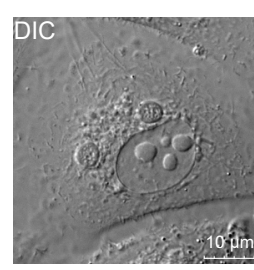

DIC
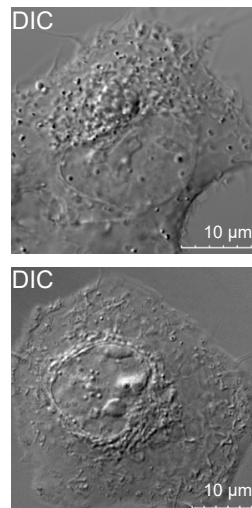

DIC

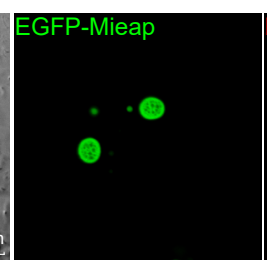

EGFP-Mieap $\Delta \mathrm{CC}$
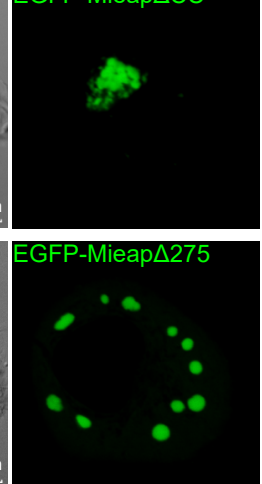

EGFP-Mieap $\triangle 496$

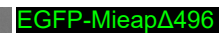

k
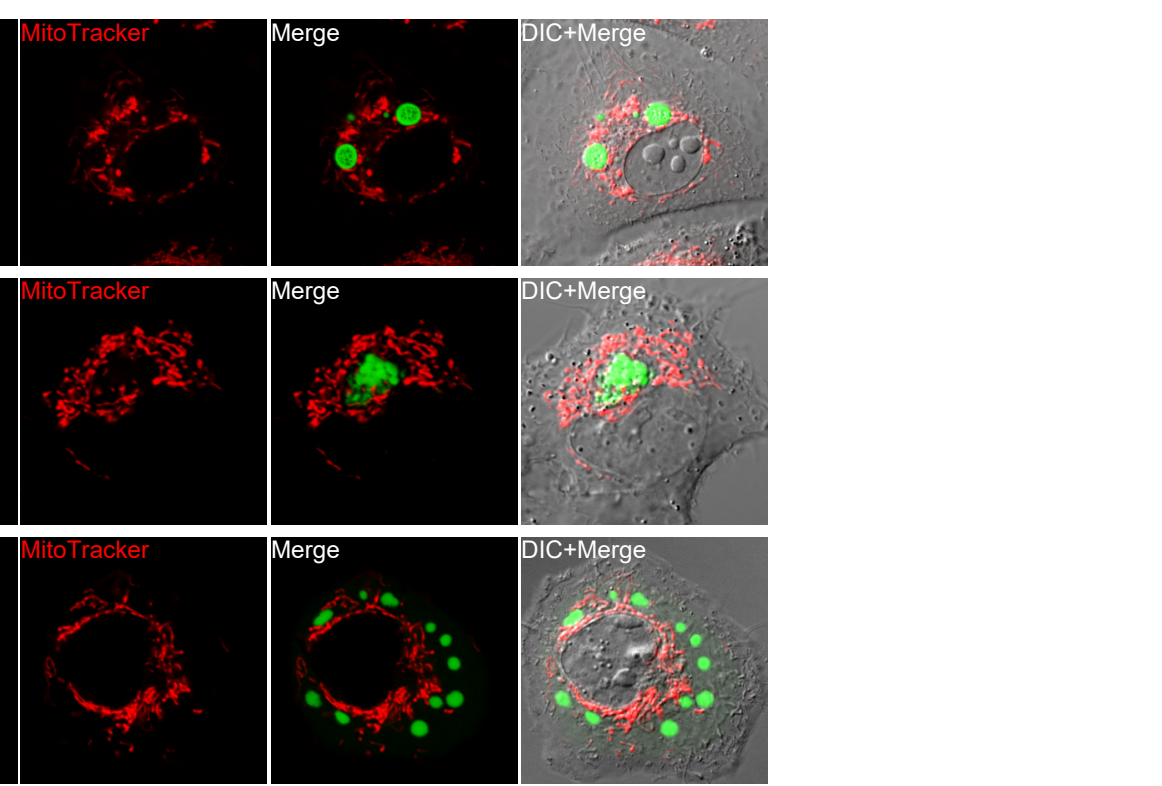

Merge
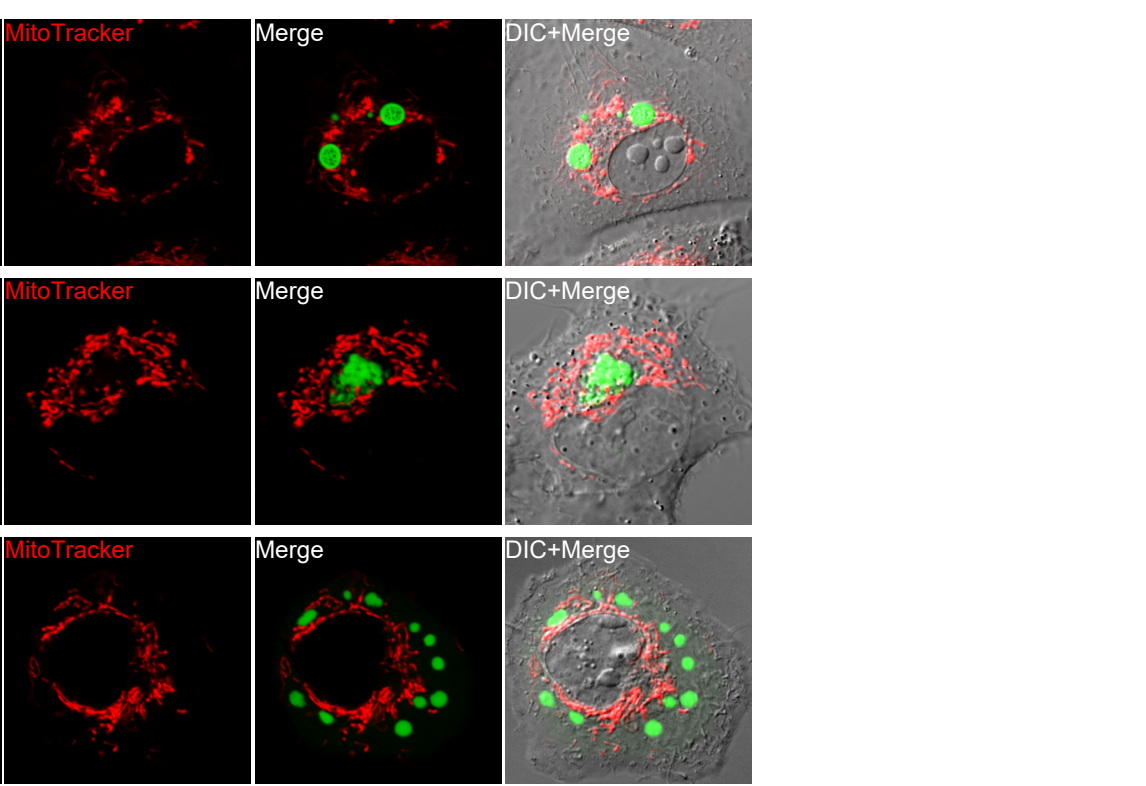

DIC+Merge

Merge

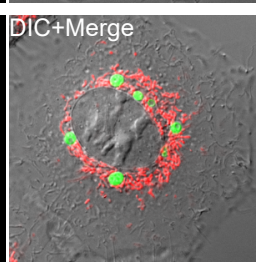


A

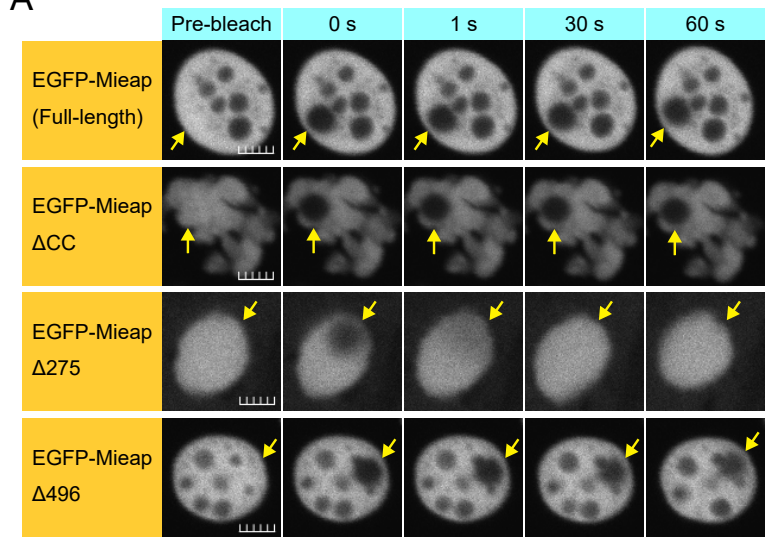

C

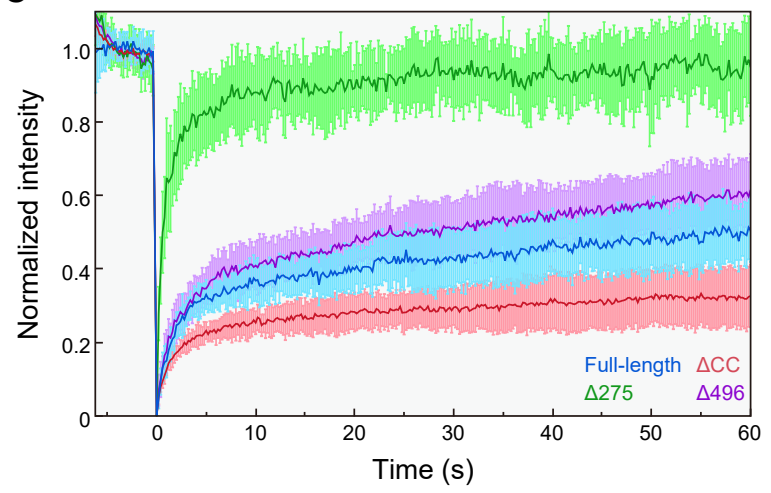

B

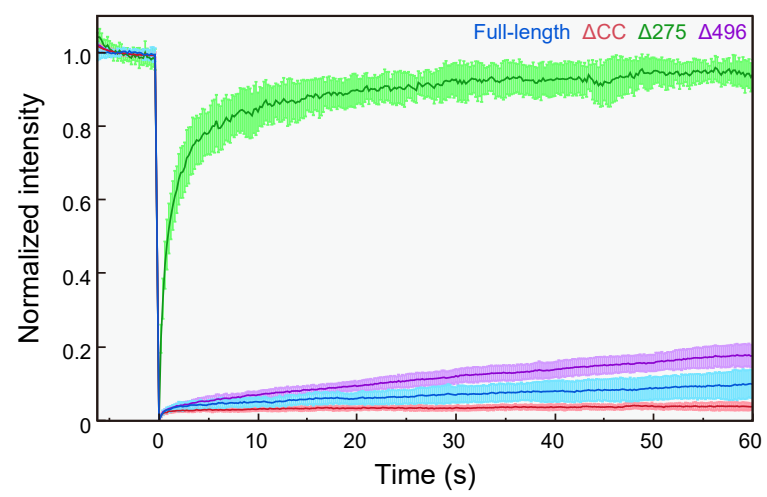

D

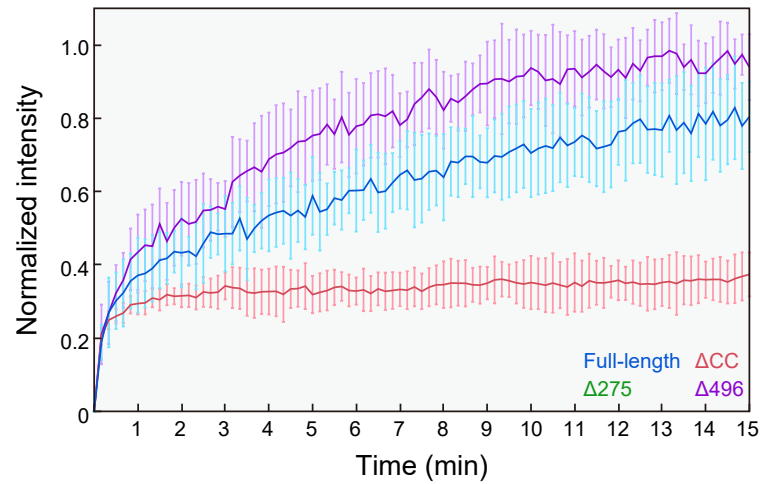


A

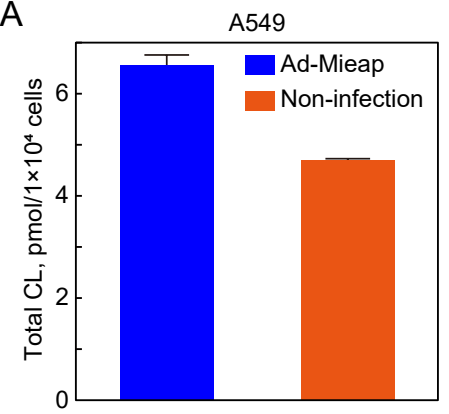

B

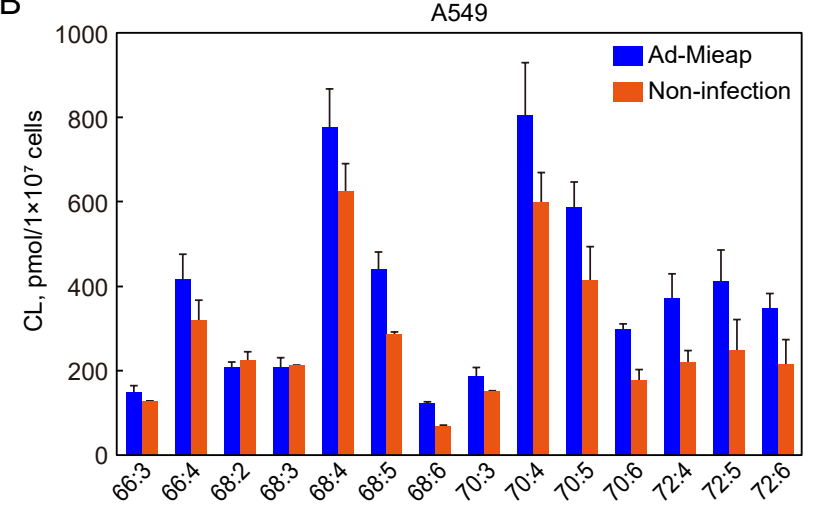

C

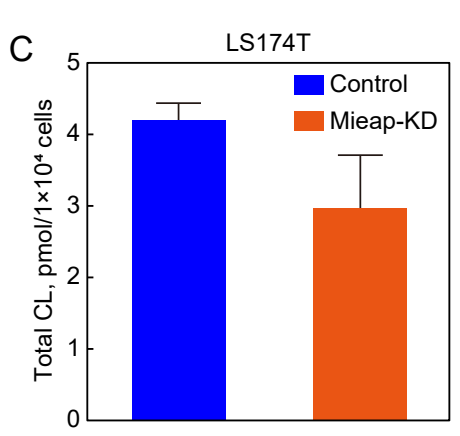

$=$

D
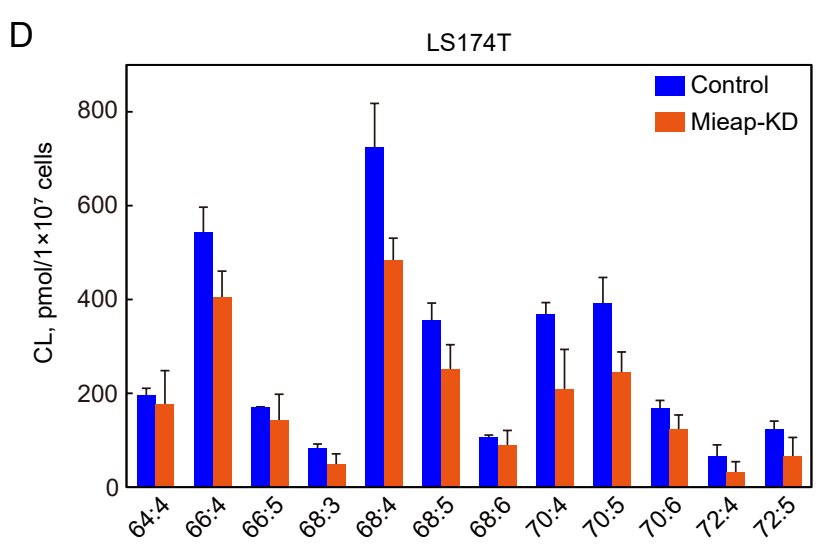
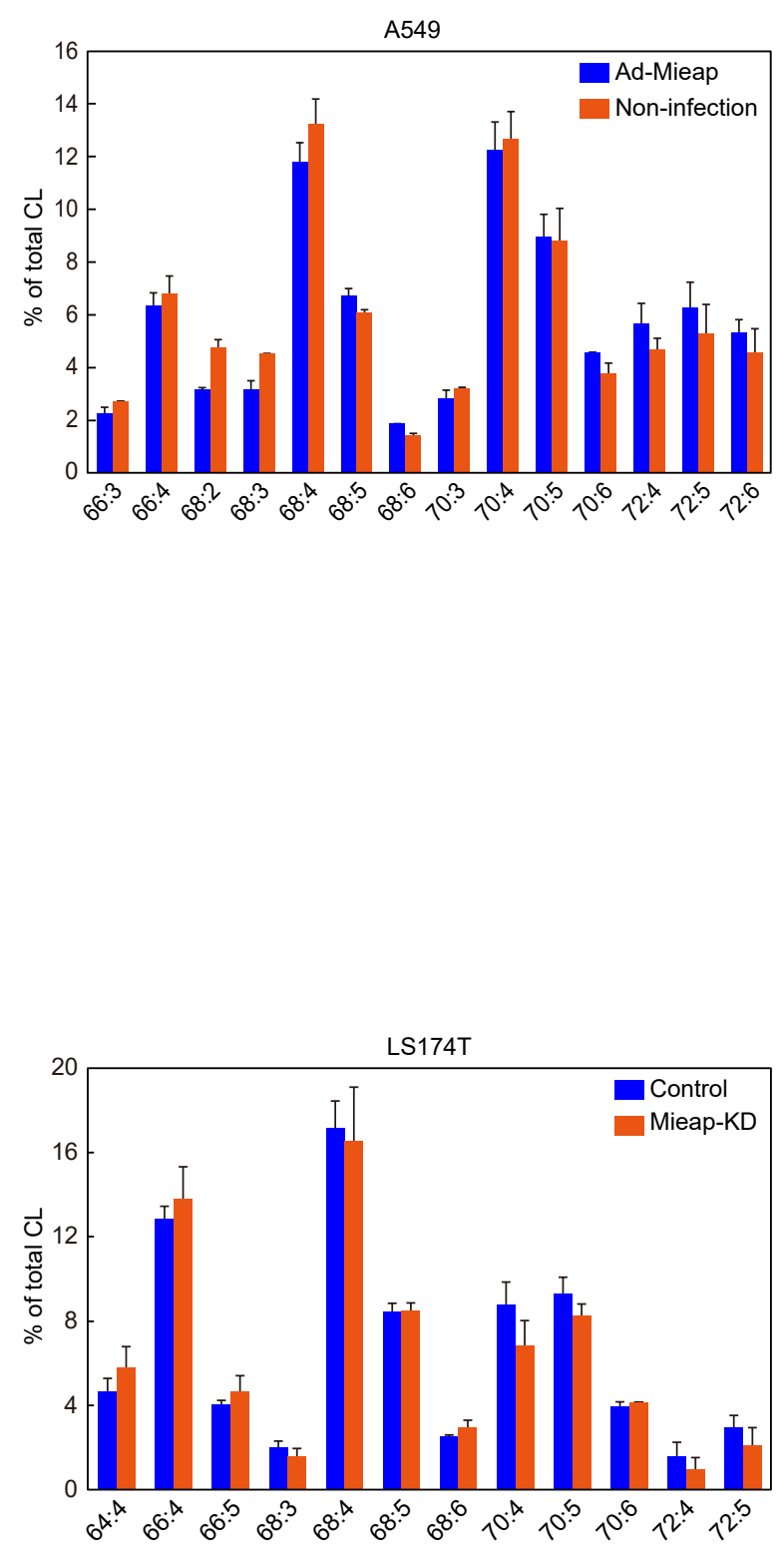
Figure 7

A

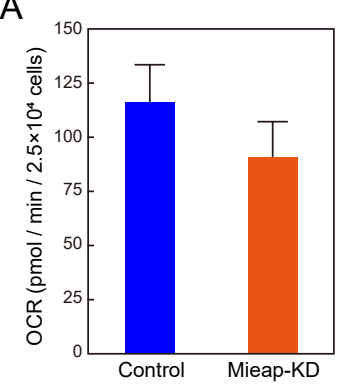

E

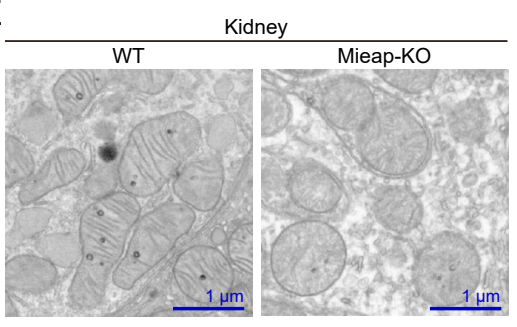

G

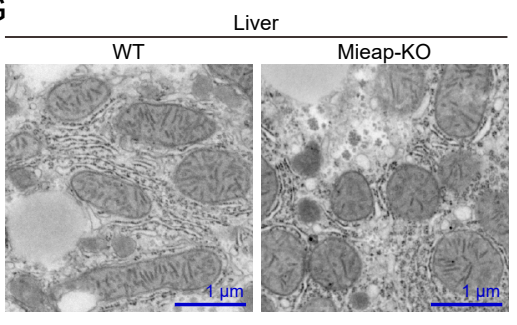

$\mathrm{K}$
B

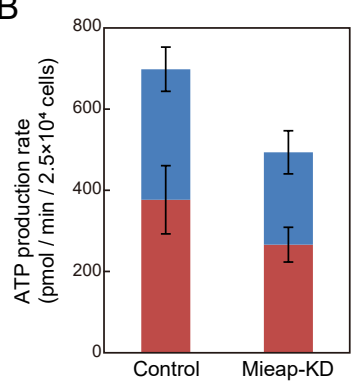

F

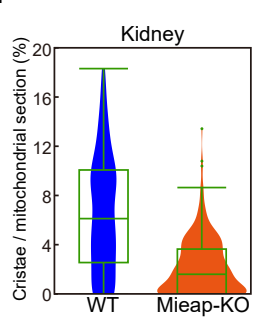

$\mathrm{H}$

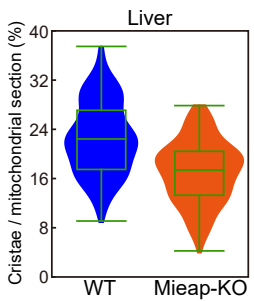

C

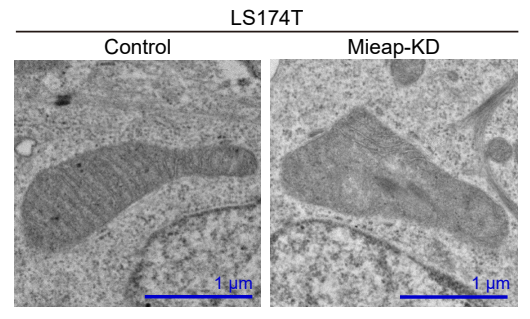

D

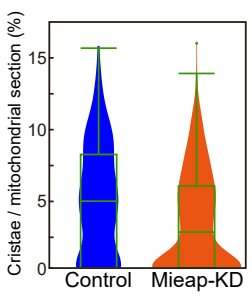

$J$

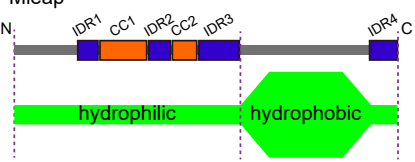

Mieap liquid droplet

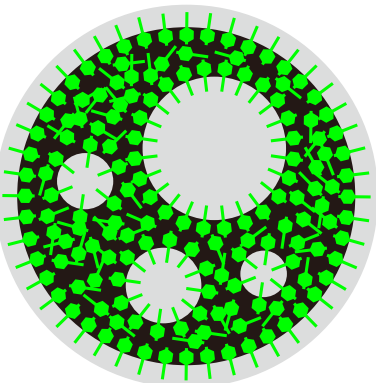

(CLM)

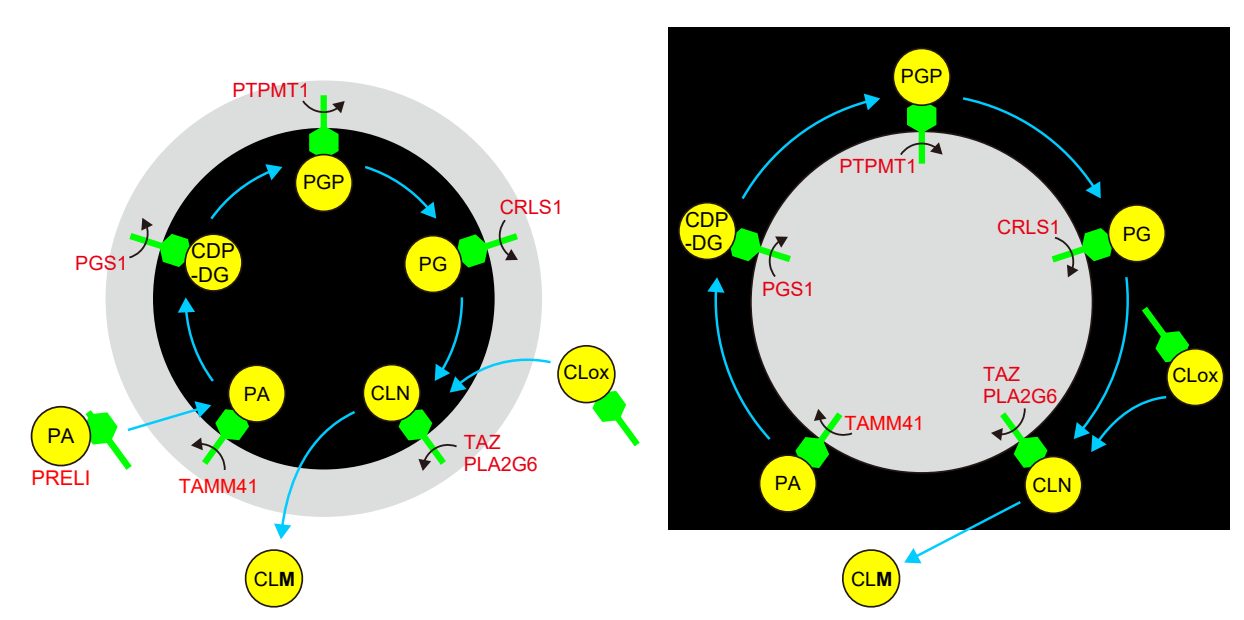

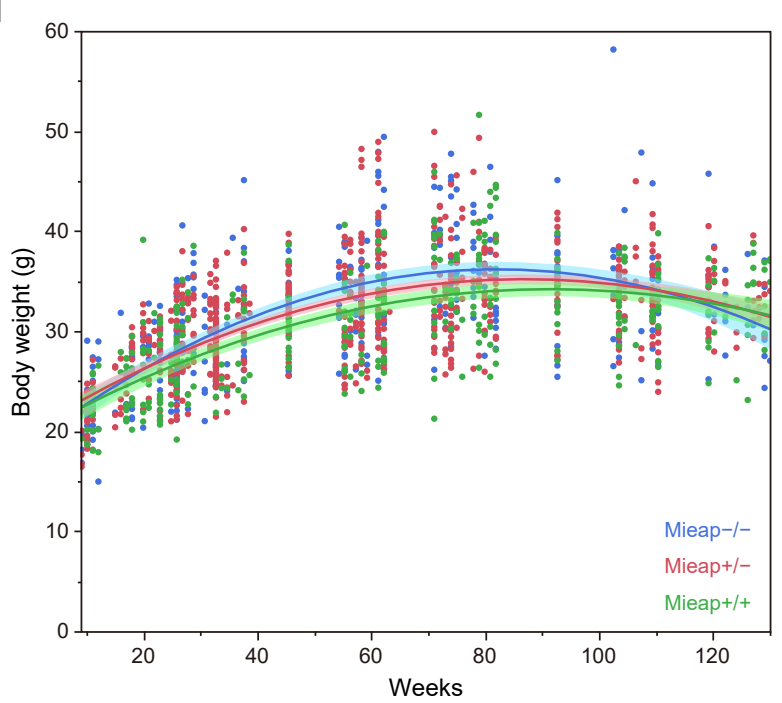

L 